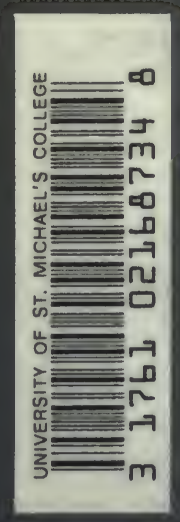




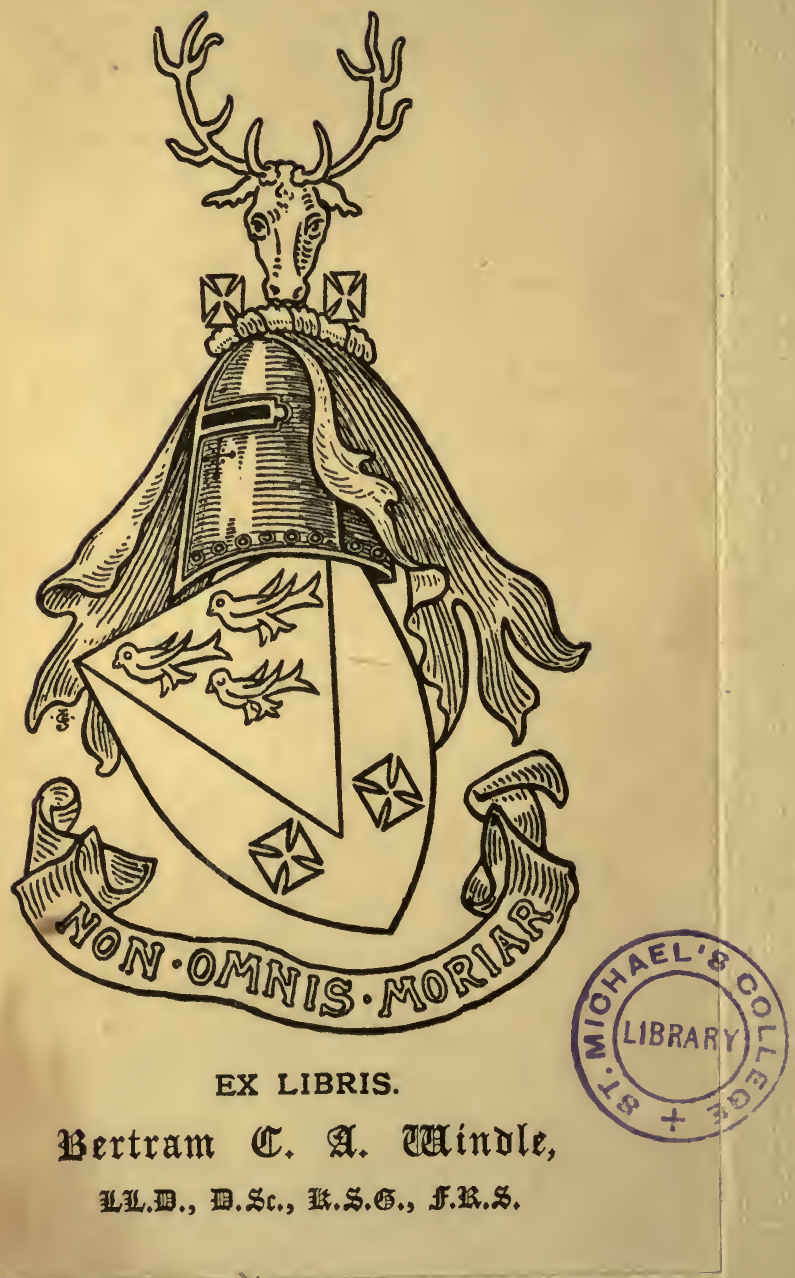


or as a living organism. He is the real man." (pp. I23-I 25.) And, it may be added, he is the man of the Schoolmen.

The argument of the book, as we have seen, is that in personality is to be found the explanation and the only explanation of the problem of life.

In actual fact we do not understand except in the most imperfect manner, the reality which lies behind the appearance of a physical world. But we understand enough to be certain that this reality has, and can have, no existence apart from personality, since existence itself has no meaning apart from spiritual existence. (p. I35.) ... In personality; there is always the element of the here and now. New experience is always, as it were; welling up within it, and gradually taking the form of new truth, and new duty. Personality is living; suffering, rejoicing, and working existence: This idea is clearly embodied in the Christian conception of God; and when we try to penetrate through the sensuous mist which blurs that conception we can see that our discussion has brought us very near to it. (p. 136.)... [Finally]: Personality is the great central fact of the universe. This world, with all that lies within it, is a spiritual world. (p. 139.)

This very inadequate skètch of a very interesting work, with the quotations which we have made from it, will at least suffice to give some idea of the author's line of argument. For its more complete development we must refer our readers to the pages of the book itself.

B. C. A. W: 



\section{MECHANISM, LIFE AND PERSONALITY}





\section{MECHA N I S M, L I FE AND PERSONALITY}

AN EXAMINATION OF THE MECHANISTIC THEORY OF LIFE AND MIND

BY

J. S. HALDANE, M.D., LL.D., F.R.S. FELLOW OF NEW COLLEGE AND READER IN PHYSIOLOGY UNIVERSITY OF OXFORD

LON DON

JOHN MURRAY, ALBEMARLE STREET 1913 


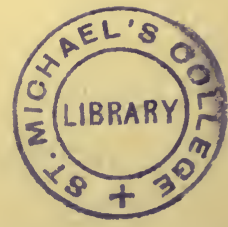

AUG 211957 


\section{PREF A C E}

'T'H Is book consists of four lectures which were delivered in the Physiological Laboratory of Guy's Hospital, during May of this year, as a London University course for senior students. They are reproduced in the form of their delivery, after careful revision, in which $I$ have been much aided by the criticisms and suggestions of my friend Professor J. T. Wilson, F.R.S.

Philosophical readers who may have chanced to see an essay by my brother and myself on 'The Relations of Philosophy to Science' in Essays in Philosophical Criticism, published in 1883, will recognise in these lectures a development of the ideas put forward in that essay. In a presidential address which I delivered in 1908 before the Physiological Section of the British Association, and in other scattered papers, the same line of argument in relation to the aims of biology and 
its position among the sciences was followed out in certain directions. The lectures now published represent an attempt at a more comprehensive treatment of the subject.

The time is now more than ripe for bringing the great biological movement of the nineteenth century into definite relation with the main stream of human thought; and these lectures form a contribution towards the fulfilment of this task. 


\title{
CONTENTS
}

\section{LECTURE I}

\begin{abstract}
The Mechanistic Theory of Life, . . . 1

\section{LECTURE II}

Criticism of the Mechanistic Theory, . . 31

\section{LECTURE III}

Biology and the Physical Sciences, . . . 66

\section{LECTURE IV}

Personality, . . . . . . . 106 



\section{LECTURE I}

THE MECHANISTIC THEORY OF LIFE

THE aim of the first two of these lectures is to examine the hypothesis that living organisms may be regarded as conscious or unconscious physical and chemical mechanisms, and can be satisfactorily investigated from this standpoint. In this first lecture I shall endeavour to state, as well as I can, the case for what may be called, in the absence of a better expression, the mechanistic theory of life.

The researches of countless investigators have established with practical unanimity certain very fundamental facts with regard to living organisms. One of these is that the matter of which the bodies of organisms are found by analysis to be composed consists of the same chemical elements as are found outside the body, and that no new matter is formed in the body, or disappears 
from it. All the matter which is found in the body, or which passes from it, can be accounted for by what is taken up from the environment. Of the particular chemical substances, moreover, which have been found in the body a large and ever increasing number can be formed artificially outside it, and there is no reason for believing that any ultimate difficulty will be experienced in artificially forming any of the chemical substances which have been discovered, or are ever likely to be discovered, within the body.

2 Another fundamental fact is that the whole of the energy which is liberated in the body, whether as heat, mechanical work, or in other forms, can be traced to sources outside the body. The actual external sources of energy in the living body were first pointed out in general terms by Mayer more than stxty years ago, and the exact investigations of subsequent physiologists have completely verified his general conclusions.

The two great physical laws of conservation of matter and conservation of energy can thus be extended with apparently rigorous 
accuracy to all living organisms, including human beings. From this it may be inferred that, however complex may be the changes involved in organic activity, they are nothing but changes in a material system. As yet we are far from being able to trace this system and its changes completely; but the main outlines are clear, and the gradual filling in of details can only be a matter of time, though we shall probably never succeed in completely filling in all the details.

It is true that, in the case of at least the higher organisms, consciousness accompanies some of the material changes in the living body, whereas consciousness is not known to accompany material changes in the inorganic world. Of this mysterious accompaniment we can of course give no physical account. Possibly consciousness accompanies all material change; but whether or not this is the case, consciousness seems to make no difference in the end to the physical and chemical chain of events. It might, conceivably, be a form of energy, generated under certain unknown conditions in active protoplasm; but, if so, it is only one form 
of energy, generated from and immediately passing back into other forms. Cut off the oxygen supply to the brain, and consciousness ceases within a few seconds. It makes no difference to the energy balance of the body whether an animal is conscious or not; and it seems simplest, in the present state of knowledge, to treat consciousness as an accompaniment, not altering in any way the physical and chemical changes which it accompanies, of certain intra-protoplasmic changes.

'The mechanistic theory may be supported by another set of considerations, which appeal very strongly to many scientific investigators. In all biological investigations we are investigating either structure or activity; and when we come to details we find that the structure is physical and chemical structure, and the activity physical and chemical activity. Hence biology can be nothing but the physics and chemistry of organisms.

This argument may be illustrated in almost infinite detail. Let us suppose that we are engaged in anatomical investigation. With the scalpel, microtome, microscope, fixing 


\section{PHYSICAL AND PHYSIOLOGICAL، METHODS 5}

and staining reagents and other physical or chemical apparatus we separate out or render distinguishable the details of structure. But these details are only details of form, size, colour, physical or chemical characters, and spatial relations to other parts. The facts we ascertain are physical and chemical facts; and the methods we use are physical and chemical methods.

If, on the other hand, we are making a physiological investigation, the same is no less true. If we are investigating secretion we are measuring the mass or volume of the substances secreted, or their chemical composition, or perhaps their osmotic pressure, or concentrations of ions in them. If we are investigating muscular contraction we are measuring the rate and extent of the contraction, or the accompanying heat production or chemical or electromotive phenomena. The phenomenon which we observe is always some physical or chemical change. The methods we use are physical and chemical methods, and the resulting facts are consequently physical and chemical facts.

From the very nature of its methods and 


\section{THE MECHANISTIC THEORY OF LIFE}

facts, therefore, biology can apparently be nothing but applied physics and chemistry. When we come to matters of detail it appears that biology does nothing, and can do nothing, but ask physical and chemical questions, and obtain physical and chemical answers, in so far as the answers are more than partial answers. In tracing, say, the development of an organism, or investigating the process of secretion, we, of course, obtain, in the present state of knowledge, only partial answers. We may not be able to give a complete statement in physical and chemical terms of the processes of development or of secretion; but it remains true, nevertheless, that the facts we are ascertaining are apparently nothing but physical and chemical facts, however imperfectly defined. Beyond these facts all is more or less empty speculation, which scientific men would probably do well to avoid.

For further support the mechanistic theory can appeal to the actual history of biology, and particularly of physiology. Apart from the constant controversies (to which reference will be made shortly) between mechanists 
and non-mechanists, the history of physiology displays uninterrupted progress in the successful application of physical and chemical methods to physiological problems. To take only a few examples, the principles of mechanics were applied by Borelli to elucidate the action of the muscles on the limbs. Kepler applied the principles of optics to the action of the eye in vision. Harvey established and analysed the facts relating to circulation of the blood by the application of purely physical observation and reasoning. As a result of the great advance in chemistry at the end of the eighteenth century the fundamental facts with regard to respiration and its relation to nutrition and animal heat were discovered; and since then the application of chemical methods to physiological problems has been continued with unbroken success. In more recent times the advance of physical chemistry has placed new and powerful weapons in the hands of physiologists. It is doubtless the case that the application of chemistry to physiology has also shown us that the chemistry of life is far more complex than 
was formerly suspected. This, however, cannot legitimately be used as an argument against the mechanistic theory: for the progress which has been made by applying chemical methods is solid progress, to which there has been no set-back, though the goal has turned out to be further away than appeared to be the case about the middle of last century, at the time of the general movement among physiologists towards the mechanistic theory. It is, perhaps, on the chemical side that physiology has made its most striking advances in recent times; but on the physical side the advance has also been continuous.

We may now turn to some of the arguments which have been used in favour of a non-mechanistic interpretation of biological facts. Perhaps the most striking fact with regard to physiological phenomena is the evidence they present of activity co-ordinated in such a manner as to conduce towards the survival of either the individual or the species. Co-ordination of a similar striking kind is not found anywhere outside the organic world; and the mere existence of this co-ordination 
has been taken as strong evidence for the presence in living organisms of some coordinating influence apart from blind physical and chemical forces.

The reply to this argument is that many of the mechanisms by which co-ordination is brought about have already been discovered, and that every year more is being discovered about them. Descartes, in his writings about the nervous system, was the first to point the way in this line of discovery. He suggested nervous mechanisms, by means of which afferent stimuli and muscular responses are co-ordinated; and since his time the theory that the nervous system is at bottom nothing more than a complex system of reflex mechanisms has been experimentally verified in many directions, and has now become a generally accepted physiological doctrine. The reflex actions associated with consciousness are evidently so complex that their gradual analysis may take generations of research work. We have also to bear in mind that many forms of nervous activity are excited or influenced by chemical stimuli acting, not on peripheral afferent nerves, but on the central nervous 
system. Thus the nervous mechanism by which the breathing is so regulated as to bring to the lungs just the requisite quantity of air, in spite of rapid and enormous changes in the volume of air required, is actuated by chemical stimuli conveyed to the respiratory centre by the blood which bathes it. The nervous or other mechanisms by means of which the activity of the heart and the distribution of blood in different parts of the body are properly regulated have also been to a large extent elucidated.

It is not, however, in connection with the nervous system only that co-ordinating mechanisms have been discovered. It has been known for long that chemical substances produced by the activity of one organ are conveyed by the blood to other organs, in which they excite activity of such a nature as to maintain the normal structure, composition and functional activity of the body as a whole. Thus the secretory action of the kidneys varies according to the nature and amount of the various substances discharged into the blood, or withdrawn from it, by other organs. If, for instance, an excess of water is taken up 
from the intestines, it is rapidly got rid of through increased excretion by the kidneys: while diminished excretion balances excessive withdrawal of water from the blood, as by sweating. The kidneys respond in a similar manner to excess of urea, sugar, inorganic salts, acids, or alkalies, etc., the result being that the normal composition of the blood is kept constant within small limits. Another similar case is that of the liver, which forms or discharges various important substances in response to chemical stimuli conveyed through the blood. Physiological investigation is constantly discovering new cases in which the activity of one organ is excited by the chemical products of activity in other organs. In all these cases the response follows the stimulus, the cause the effect, with unerring accuracy. Apart altogether from the nervous system, therefore, the body is full of mechanisms for the co-ordination and control of functional activity. The nervous system, indeed, has come in recent years to appear much less important than was formerly supposed in the co-ordination of physiological activity; and it seems to be only in cases 
where very rapid control is required that the nervous system plays an important part.

It is not merely in the case of functional activity that chemical stimuli play an important part: for evidence is now steadily accumulating that the co-ordination of growth and maintenance in different parts of the body is dependent on the action of chemical substances conveyed from part to part by the blood and lymph circulation, or by simple diffusion from one contiguous part to another. Some of the most striking evidence in this direction has been afforded by the extraordinary effect on growth and nutrition which is produced by removal or disease of such organs as the thyroid gland or the pituitary body. Absence of the thyroid completely arrests growth, and influences in other ways the normal structure of the body; but these effects can be annulled by the administration of an extract of the thyroid from another animal. Hence even such a very small organ as the thyroid produces chemical substances which excite and control the nutrition of other parts. Another well-known case is the influence of changes in the generative organs on the 
growth and nutrition of distant parts of the body. Although the evidence is, owing to the great chemical and experimental difficulties, accumulating but slowly at present, we cannot doubt that the growth and maintenance of every part of a living organism is controlled by the chemical stimuli derived from other parts, or from the environment.

There thus appears to be no difficulty in regarding a living organism as a complex system of physico-chemical mechanisms, each of which is controlled by the rest in such a way that the normal structure and activity of the organism is, under ordinary conditions, maintained. We can, moreover, verify the existence of these mechanisms, one by one, by exact experiment; and their actual existence has already been verified in a large number of instances. Hence the co-ordination of growth and activity, as found in living organisms, presents, in itself, no real difficulties for the mechanistic theory.

We have still to account for the existence of physico-chemical structures possessing the marvellous characteristics of living organisms -so different from anything found in the 


\section{THE MECHANISTIC THEORY OF LIFE}

inorganic world. Here the genius of Charles Darwin has provided an explanation in harmony with the mechanistic theory. No type of organism can survive in which the physiological mechanisms are not so constituted and so co-ordinated that the organism is capable of completing a life-cycle culminating in the transmission of a similar structure to its descendants. Those organisms and their descendants which have varied in structure in a direction which gives them a smaller probability of surviving will become extinct in the fierce struggle for existence which prevails everywhere among living organisms. On the other hand, those which have varied in such a direction as to give them a greater probability of surviving will increase and multiply, displacing the inferior types. Hence by the blind operation of natural selection through countless ages higher and higher types of organism will be produced.

The wonderful complexity, accuracy, and co-ordination of the physiological mechanisms found within the bodies of living organisms can thus be accounted for on purely mechanical principles. All that it is necessary to 
assume is that organisms transmit their structure to their descendants, but in such a manner as to permit of slight variations, on which natural selection then acts in such a way that the structure is, generation by generation, more and more perfected and elaborated. With this perfecting of the structure which makes for the survival of the species there, of course, goes hand in hand the elaboration of the mechanism needed for securing the inheritance of the more perfect structure.

On the essential mechanism of hereditary transmission, recent investigation, and particularly the work of Weismann, has thrown a flood of light. The germ-plasm, from which parent and offspring are alike developed, is, we have now reason to believe, passed on qualitatively unaltered, or almost unaltered, from parent to offspring. It is constantly increasing in amount by a simple process of growth or quantitative increase; but as regards chemical structure and composition it remains the same. The offspring resembles the parent for the simple reason that both originate from material which is qualitatively identical, and which is placed originally in qualitatively the 


\section{THE MECHANISTIC THEORY OF LIFE}

same physical and chemical environment. This being so, the only possible result is that the offspring resembles the parent.

The actual origin of living organisms from inorganic matter is still wrapt in mystery. We have not yet succeeded in producing in the laboratory anything really resembling any known living organism. This, however, is not to be wondered at, since all the organisms which we at present recognise as such are now known to be descended through countless generations from their first progenitors. Throughout these countless generations natural selection has continuously acted, gradually evolving a complexity of structure which we can never hope to imitate by laboratory experiments.

It is possible, nevertheless, to imagine how life may have originated. We can now form in the laboratory carbon compounds with protein characters which approach in some degree in complexity to the natural protein compounds found in protoplasm; and we may assume that the first step towards the origin of life was the formation by natural means of some variety of protein 
material. The complexity of the protein molecule is enormous, and its capacity of entering into chemical or physical combinations with other molecules is so great that in it we seem to see the possibilities of the evolution of something possessing the primitive characteristics of life. We can imagine such molecules combining by aggregation until the aggregate becomes unstable and divides into two aggregates, each possessing all the original properties of the first, and being capable of similarly growing and dividing. If the conditions are such that this process can go on continuously, and that new protein can constantly be produced, as is actually the case in : agetable tissues, natural selection will soon come into play, and the evolution of a less imperfect, and more definite and complex, form of organism will gradually take place.

A further part of the case for the mechanistic theory consists in criticisms of alternative theories. The traditional opponents of the mechanistic theory may be classed as either vitalists or animists. The former maintain that the behaviour of living organisms is so peculiar, and so different from anything met 
with in the inorganic world, that we must assume that the processes occurring in living organisms are guided and determined by some non-physical factor best known as the 'vital force' or 'vital principle,' but in recent times appearing under various other names. This factor is assumed to act blindly and unconsciously, and to be in action at all parts of the body. The animists also assume a non-physical factor; and this they identify with the soul, which is supposed, however, to act sub-consciously. For the purposes of the present argument the animists may, perhaps, be classified along with the vitalists, as the differences between them are for the present purpose very small.

Although outspoken vitalism has now become somewhat exceptional among biologists, or physiologists, and the prevailing opinion is in favour of the mechanistic theory, yet vitalism in a modified form seems to be constantly cropping up in biological literature. The reasons for this are, in part at least, fairly evident. We have only to look back to the writings of some of the leading advocates of mechanistic ideas in biology to 
see that in many instances simple mechanical theories of various physiological processes were put forward without sufficient experimental evidence of their correctness. Subsequent investigation has often shown that these theories were incorrect, and this result has seemed to be a justification for returning to the prevalent vitalistic ideas of earlier times.

As an instance of this we may take Ludwig's early theory as to the process by which urine is secreted. He supposed that urine is separated from the blood in the glomeruli of the kidney by a process of simple filtration, and that the dilute liquid thus formed is concentrated during its passage down the tubules by a process of osmosis, in which water passes from the tubules back into the blood, leaving the fully formed urine as a relatively concentrated liquid which passes out towards the ureter. This theory turned out, when experimentally tested, to be far from correct. It is the cells lining the tubules of the kidney which are the active agents in the secretion of urine; and they act against osmotic pressure, picking 
out from the blood, and forcing into the ducts of the tubules the various constituents of urine. Such a mode of statement seems to approximate very closely to vitalism, although, as already pointed out, we have only to presuppose the existence of suitable intra-cellular mechanisms in the cells lining the tubules in order to fit the observed facts with the mechanistic theory of life.

As another instance we may take the case. of oxidation processes occurring in the living body. It was formerly believed that physiological oxidation is a comparatively simple process, varying in rate, like ordinary oxidations occurring outside the body, with the supply of oxygen on the one hand, and of oxidisable food-material on the other. When, however, the matter came to be investigated by Pfluger and others, it was found that this was not the case : for the supply of oxygen and of food-material could be varied within wide limits without altering the rate of oxidation. Hence it was concluded that the living cell regulates its own oxidation processes, and, indeed, all chemical processes occurring within it. This appears to be a 
very vitalistic form of conclusion: for some independent factor seems to be postulated which regulates the chemical processes occurring within cells. From the standpoint of the mechanistic theory, however, all that need be assumed is that the chemical processes occurring within living cells are far more complex than was at one time supposed. For one thing, intra-cellular ferments or enzymes seem to be largely concerned in intra-cellular changes. If, therefore, oxidations and other intra-cellular chemical processes are dependent on the liberation of enzymes, we can readily understand why these processes do not increase or diminish in the same manner as the simpler processes commonly met with outside the living body. By discovering the nature of the ferments concerned, and the conditions determining their liberation and mode of action, we may hope to be able to give a complete physicochemical explanation of all the phenomena. In any case, this seems to be the only line of investigation likely to give fruitful results, and nothing could be more futile than to rest content with the theory that some 
mysterious agency is at work, the nature of which is beyond physical and chemical investigation.

It is only what might be expected on the Darwinian theory of natural selection that the physico-chemical mechanisms within the living body should turn out to be extremely complex, since these mechanisms are the product of natural selection acting through countless generations; and it is folly to go back to vitalism for the mere reason that living organisms do actually turn out to be very complex.

We must now examine the nature of the assumption made by the vitalists, and consider to what extent it corresponds with observed facts. Vitalism raises no objection to physical and chemical explanations applied in what is considered their proper place outside the intimate vital processes of living organisms. It assumes, however, that these intimate processes are guided or controlled by an influence which is manifested only in living organisms, and which acts in a manner wholly different from anything known in the inorganic world. The reason for making this assumption is 
that living organisms seem everywhere to present evidence of an autonomy of their own. They seem to go their own way, and pursue their own ends, in spite of all kinds of disturbing conditions. In a physical and chemical environment which is constantly changing in one respect or another, they develop or maintain certain characteristic peculiarities of structure and activity, and pursue a characteristic life-history. Mechanisms which would cause them to do this under the very varied conditions which they experience seem hardly conceivable. Hence we must assume in the case of each organism the presence of some influence which is constantly guiding in the right direction the otherwise blind physical and chemical processes within the living organism. This assumed influence is best known under the name of 'vital force'; but such a name is evidently unsuitable, as the word 'force' is usually employed to designate physical and chemical phenomena of a very different character. The expressions 'vital principle,' or ' entelechy' (proposed recently by Driesch) are more suitable. 
The manner in which the mechanistic theory endeavours to meet the objections of the vitalists has already been indicated, but will be examined more closely in the second lecture. Meanwhile let us see what are the objections to vitalism.

Assuming the vitalistic theory, the simplest observations show us that the action of the vital principle is dependent on physical and chemical conditions of environment, and on the physical and chemical structure of the organism. If, for instance, the temperature is too high or too low, or if the supply of oxygen, or even of some inorganic salt, is cut off, all characteristic signs of life soon cease. The same is the case if the finer structure of the living material has been seriously damaged

- by physical or chemical agents. It is thus f only under certain limiting physical and chemical conditions that the vital principle can manifest itself. Provided, however, that - these limiting conditions are present there appears, at first sight, to be a wide field for the manifestation of the influence of the vital principle. If, for instance, a certain minimum of oxygen or of food-material is 
present, the organism selects just what it requires for its growth and maintenance, rejecting or excreting all that is superfluous.

Let us examine the matter more closely, however. The further physiological investigation is carried, the more clearly does it appear that the co-ordinated action by which different parts of an organism work together for the maintenance of the whole depends on chemical substances or physical disturbances conveyed from part to part of the living substance. The behaviour of each part is not merely qualitatively, but also quantitatively dependent on these chemical and physical influences. - The respiratory centre responds to the minutest alterations in the partial pressure of carbon dioxide in the blood, and the kidney to the smallest variations in the concentrations of water or sodium chloride or hydrogen ions. Everywhere in the living body we find, on close examination, this close and accurate dependence of vital activity on the physical and chemical conditions in the immediate environment. It is, therefore, only from an outside and superficial point of view that there 
appears to be something in a living organism which acts, within limits, independently of the physical and chemical conditions of environment. The apparent autonomous selec+ tive action of the organism turns out to be causally dependent in every detail on physical and chemical conditions. The vital principle, if it exists, is therefore determined in its action by those conditions: we can never isolate and clearly identify its action. As a positive scientific working hypothesis it - is thus useless; at the best it only serves to express our ignorance of the exact means by which the parts of a living organism are caused to react in a certain manner to a given physical or chemical change. This being so, the advocates of the mechanistic theory may well ask whether vitalism has any real justification.

To illustrate the force of this question it is only necessary to refer to the main argument for vitalism in the recent writings of Driesch. As is well known he discovered that in the earliest stages of embryonic development the cells of the embryo may be separated completely from one another, or 
their mutual arrangement may be completely altered by mechanical means, and yet one of the separated cells, or the disarranged collection of cells, may develop in a perfectly normal manner. Here we have presumably disarranged the normal mechanism for development, and yet normal development occurs. From this Driesch concludes that a factor is present which acts independently of physical and chemical stimuli, and which he calls 'entelechy,' and identifies with the old 'vital force.'

Now there is no evidence at all that each cell, in growing and dividing in the one particular manner which constitutes normal development, is not determined by special - physical and chemical stimuli peculiar to its position relatively to the other cells, and to the external environment. We do not yet know what these stimuli are; but probably no physiologist would doubt that they exist, and will be discovered when our methods are fine enough. Hence Driesch's argument for an independent vital force breaks down entirely.

A further objection to vitalism is that it 
implies a definite breach in the fundamental law of conservation of energy. As already mentioned, every experimental investigation has hitherto resulted in a verification of this law in the case of physiological phenomena. Any 'guidance' of living organisms by the vital principle would imply a creation or destruction of energy; and this would be the case even if the energy created in the living substance were again destroyed before it could escape to the outside, and so become measurable. The reply that this creation or destruction of energy may be extremely small is not one which can satisfy a scientific investigator. A principle which has been verified again and again under all sorts of conditions cannot be set aside except on definite experimental evidence; and this is entirely lacking.

Still another objection to vitalism depends upon the fact that in order to 'guide' effectually the excessively complex physical and chemical processes occurring in living material, and at many different parts of a complex organism the vital principle would apparently require to possess a superhuman 
knowledge of these processes. Yet the vital principle is assumed to act unconsciously. The very nature of the vitalistic assumption is thus totally unintelligible. From this point of view also the hypothesis is useless: for even if we cannot completely understand a living organism by the aid of physics and chemistry, we do not improve matters by postulating an agency which is itself entirely unintelligible.

In one form or another these objections to vitalism have been urged repeatedly, and there has been no satisfactory reply to them. On the other hand, there have been very effective retorts from the vitalistic side against the mechanistic theory. It is not these retorts that concern us at present, however, but the inherent untenability of the vitalistic position. If the mechanistic theory is wrong, this does not prove that the theory of the vitalists is right, so that the objections to vitalism lose none of their force.

Let us now try to sum up the position reached at the end of this lecture. The mechanistic theory of life has been stated in outline. It evidently affords to biologists a 
perfectly clear working hypothesis-that the peculiar phenomena of life are due to the play of the physical and chemical environment on intra-protoplasmic mechanisms which have been evolved through the influence of natural selection acting for ages. If this theory is correct, the aim of biology is to unravel the mechanism; and biology itself is nothing but a branch of physics and chemistry, which we may, if we like, distinguish as biophysics and bio-chemistry. The alternative hypothesis of the vitalists has been shown to be unproved, unintelligible, and practically useless as a scientific working hypothesis.

In the next lecture the mechanistic theory itself will be examined. 


\section{LECTURE II}

CRITICISM OF THE MECHANISTIC THEORY

In the last lecture it was shown that the position of the vitalists is wholly unsatisfactory; but it does not follow from this that the mechanists are right; and those engaged in the observation of living organisms can hardly escape feeling an instinctive distrust of the mechanistic theory, in spite of the confidence with which it has been urged upon the world during the last fifty years. Somehow or other a living organism never seems to be a mechanism, however often it may be called one. The closer the examination, the more confirmed does this impression become, always provided that we are studying living organisms themselves, and not merely their dead bodies, or material which has been removed from their bodies.

Apart from arguments of a general or philo- 
sophical character, the main strength of the mechanistic theory arises from the fact that all physiological activity is apparently dependent on physical or chemical 'causes.' Whether the cause be physical disturbance, heat, light, or the presence of one or other of numerous chemical substances, it is always something definite. The physiologist, however, usually calls the cause a 'stimulus,' and it must in the first place be pointed out that in identifying stimulus and response with physical or chemical cause and effect the mechanistic theory makes a gigantic leap in the dark.

To make this matter clear, we may take one or two examples. A minute and scarcely measurable increase in the hydrogen ion concentration of the blood excites the respiratory centre of a normal warm-blooded animal to intense activity. Similar minute alterations in the concentration of water, or sugar, or sodium chloride, or hydrogen ions, have a corresponding influence on the secretory action of the kidney; and cases of a similar kind, where both growth and physiological activity are similarly influenced, may be multiplied indefinitely. 
In all these cases the response depends upon the 'excitability' of the responding tissue; and when we examine the matter further we find that the excitability is dependent on a very large number of conditions, most of which are presumably still unknown. Moreover, the excitability varies in response to very minute changes in the environment, just as is the case with the original response to the stimulus. The presence or absence of some bloodconstituent, normally present perhaps in only the minutest proportions, may profoundly affect the excitability of any tissue: or its response may be modified or 'inhibited' by excitation of other parts. It is true that physiologists can obtain a constant response to a given stimulus; but this is only the case if the conditions are 'normal.' In living and intact organisms nature provides us with normal conditions. The more carefully the matter is investigated, however, the more clearly does it appear that 'normal conditions' designate something of vast and unknown complexity. The fact that such conditions should be realised again and again in different individual organisms, and in the same organism at different 


\section{CRITICISM OF MECHANISTIC THEORY}

times, is so familiar that its extraordinary character, from the physical and chemical standpoint, usually escapes attention.

It may be urged that the immense complexity and delicacy of the physical and chemical conditions on which physiological responses depend does not in itself furnish any reasons for doubting the mechanistic theory of life. This is doubtless true; but the point must be emphasised that in the case of stimulus and response there is in reality no experimental evidence whatsoever that the process can be understood as one of physical and chemical causation. In the case of physiological stimulus and response no real quantitative relation can be traced between the supposed physical or chemical cause, and its effect. When we attempt to trace a connection we are lost in an indefinite maze of complex conditions, out of which the response emerges. It is of little use to point out that in many cases the determining cause of a physical or chemical change may be something very small as compared with its effect. The turning of a switch, or opening of a valve, or application of a tiny spark, may, for instance, produce gigantic 
effects. In all these cases we can trace the chain of cause and effect, whereas in the physiological case we cannot. Let it be granted that hope may be entertained of some day tracing the physiological chain. It is nevertheless clear that the existence of such a hope, however confidently expressed, must not be confused with evidence. ${ }^{1}$ In recent years it has become the custom to speak of the 'mechanisms' of physiological activities. Until these supposed mechanisms have been actually discovered it would be better not to use language which implies far more than what our present knowledge warrants.

'The failure to be able to trace, at present, the causal chain between stimulus and

${ }^{1}$ It appears to me that a very striking instance of this confusion is furnished by the reasoning which runs through Professor Loeb's recently published essay on The Mechanistic Conception of Life (Chicago, and Cambridge University Press, 1912). Thus after describing the observation that an unfertilised ovum may be excited to development by various means, such as placing the ovum for a short time in hypertonic sea-water, or simply piercing its outer membrane with a needle, Professor Loeb proceeds to draw the extraordinary conclusion ' that the process of the activation of the egg by the spermatozoon, which twelve years ago was shrouded in complete darkness, is to-day practically reduced to a physico-chemical explanation.' 
response implies equal failure in tracing the stream of matter or of energy through a living organism. We cannot tell what exactly becomes of the atoms and molecules which pass into the body - how far, or in what sense, they are built up into the living tissue, or in what way their potential energy is immediately utilised. We must not mistake measurements of the balance of matter or energy entering and leaving the body, for information as to the manner in which this stream passes through the living tissues.

In the previous lecture we saw that in the historical development of physiology there has been a continuous accumulation of facts, obtained by the application of physical and chemical methods to physiological phenomena. The limits which the vitalists have attempted to set to this accumulation of knowledge have been broken down again and again, and there is no reason to suppose that there are any limits. The leaders of the mechanistic physiology have been completely justified to this extent, and we may rest assured that to this extent physiology will never go back on the step which they took. Our knowledge as to 
physical and chemical conditions which determine excitation and excitability, taking these words in their widest sense as applying to the whole of the elementary phenomena with which physiology and morphology deal, has grown continuously, and will continue to grow. No physiological or morphological phenomenon is beyond investigation on similar lines; but the results of such investigation are by no means identical with the gradual establishment of a definite causal connection between stimulus and response. There has been much unconscious confusion on this point.

We must now proceed to examine the belief, at present very prevalent, that the progress of physiology is leading to a gradual verification of the mechanistic theory of life. It has already been pointed out how dependent the progress of biology, and particularly of physiology, has been on that of physics and chemistry. 'This undoubted fact has been taken as evidence that physiology is becoming a physical and chemical science, and has commonly been coupled with the assertion that with the help of these methods c 2 
great progress has been made in resolving physiology into 'bio-physics' and 'biochemistry.'

Now it does not follow at all that because physiology makes use of physical and chemical knowledge and methods it must be nothing more than physics and chemistry. All depends upon the nature of the facts revealed by the use of these methods. We might as well argue that because physicists and chemists make use of their sense-organs and brains their science must be a branch of physiology. The real question concerns the nature and general tendency of the conclusions actually attained by physiologists, by whatever legitimate means these conclusions have been reached.

In surveying the general trend of physiological progress it is somewhat difficult to know where to begin. From the early modern times we find the idea present that the activity of some peculiar agency distinguishes living from non-living things. At the time of Descartes, for instance, it was generally held that apart from the conscious animal spirit or soul, a living body is domin- 
ated by specific agencies known as the vital and vegetative 'spirits.'

Descartes was the first to put forward a thorough-going mechanistic theory of the working and developnient of the animal body. His De Homine and De Formatione Foetus are works of great biological interest, on account of their influence on subsequent thought. The body is represented, in so far as physiological knowledge extended at the time, as nothing but a piece of mechanism; and its development is also represented as a simple mechanical process. The animal spirits are depicted as a subtle fluid separated and filtered off into the ventricles of the brain by a purely mechanical process. The afferent nerves are supposed to be fine fibres leading up to the ventricles of the brain and connected with valves opening or closing the upper ends of the efferent nerves. These latter are supposed to be tubes conveying the animal spirits from the ventricles. As a result of any sensory or afferent stimulus the threads are pulled, and the connected valves consequently opened, with the result that the 'animal spirits' rush 
down into the muscles supplied by the efferent nerves, distending them and thus causing them to shorten. According to the arrangement of nerve-fibres or tubes, and valves, one form of reflex action or another follows any given sensory stimulus. The chief motive power for the whole of the mechanisms by which Descartes suggested that the human body is worked and development brought about was furnished by supposed rhythmical expansions of the blood in the heart, owing to chemical explosions.

The greater part of the physiology of Descartes was extremely crude, and lacking in experimental foundation. This crudeness stands out in strong relief against the far sounder, but at the same time far more limited, observations and reasoning of Harvey, whose writings had greatly influenced Descartes. Nevertheless the mechanistic ideas first put forward in a thoroughly systematic form by Descartes have continued to influence biology up to the present day.

If we trace the history of physiology onwards from the time of Descartes we find constant conflict between mechanistic and 
non-mechanistic theories, with all sorts of intermediate shades of opinion. The physical and chemical mechanisms assumed by Descartes and others who succeeded him were gradually proved to be non-existent or non-effective, and new mechanisms took their place. With each new discovery of structure or function there came fresh modifications of mechanistic theories, and fresh objections to them. The discovery of respiratory exchange in the latter part of the eighteenth century, the subsequent general application of chemistry in physiological investigation, and the introduction of the compound microscope early last century, were potent factors in this development.

Up till nearly the middle of last century the prevailing physiological opinions were on the whole more or less vitalistic, and they are fairly reflected in Johannes Müller's famous text-book of physiology. Physical and chemical explanations of all processes occurring outside the actual living substance of the body were freely accepted, for instance, for all that happens in the liquids enclosed within the body and for its external mechanism 


\section{CRITICISM OF MECHANISTIC THEORY}

generally. The finer regulation of growth, nutrition, muscular and nervous functions, was believed to be regulated by the 'vital force.' Müller had himself taken a prominent part in disproving by his microscopical observations on glands the mechanistic theories previously prevailing with regard to secretion, and his numerous observations on growth and development had led him in the same direction.

Among the younger physiologists about the middle of the century there arose, however, a very strong reaction against vitalism and in the direction of mechanistic theories. Schwann, the discoverer of the fact that the bodies of the higher animals are made up of cells, believed that he had also discovered that cells are deposited from the body liquids by a process akin to crystallisation. This hypothesis, of course, struck at the very roots of vitalism. Within the next few years attack after attack was aimed at all the apparent strongholds of vitalism. Du Bois Reymond published observations pointing to an electrical theory of propagation of nerve impulses; Ludwig and others devised new 
mechanical theories of secretion and absorption; Liebig, though himself a vitalist, put forward purely chemical theories of various physiological processes; Mayer pointed out the source of the energy of animal movement; and last of all came the publication of Darwin's Origin of Species.

Vitalism itself was also vigorously and directly attacked, and its utter weakness pointed out. Perhaps no more clear and convincing demonstration of the untenability of the vitalistic position has ever been given than in du Bois Reymond's introduction to his Untersuchungen über thierische Elektricitat published in 1848.

The momentum of the intellectual movement of that time has lasted to the present day, and the influence of this movement has spread in ever-widening circles. But we are not concerned with this, nor with the fate of vitalism, but with the further progress of the experimental verification of the mechanistic theory. From this standpoint all that can be said is that the mechanistic theory has, on the whole, fared very badly. Schwann's simple mechanical theory of growth was based on 


\section{CRITICISM ${ }^{\circ}$ OF MECHANISTIC THEORY}

imperfect observation, and has long been abandoned. We now know that all cells are formed by division of pre-existing cells, and that the problem of the process of cellgrowth and cell-nutrition is not one which we have at present any prospect of solving in a mechanistic direction. Nor is it any better with the problems of secretion and absorption. Thanks to the work of Ludwig himself, of Heidenhain, and a host of other investigators, we now know far more than was known at the middle of last century about secretion and absorption; but their 'mechanism' is further away than ever. When Johannes Müller suggested that the processes of secretion and absorption are akin to the processes of growth he was doubtless far nearer the truth than his immediate successors: for secretion and absorption are evidently only phases of the many-sided metabolic activity which we designate by the name of cell-life. We have made great progress in learning how manysided, and how orderly, this cell-life is, but none at all in explaining how this life is ordered and maintained. 


\section{RECENT PHYSIOLOGICAL PROGRESS 45}

The simple chemical theories of the respiratory and other metabolic processes occurring in the body have likewise disappeared. The work of Pflüger, Rubner, and others has proved that in the living body all these processes are regulated with the utmost nicety, and that the seat of the regulation lies within the living cells of the body. By what physical or chemical process regulation is brought about we do not know. We have not even discovered the agents employed in the process, although, as already pointed out, there is reason to believe that, in many instances at least, these agents are intra-cellular enzymes.

It has become evident also, that no simple physico-chemical theory of muscular or other physiological movements will suffice. The processes which determine visible movement, or transmission of excitation in living cells, are an integral part of the many-sided activity of the living cell, so that the elementary problems of physiology cannot be solved piecemeal. A physico-chemical explanation of muscular movement, or of secretion, or cell-nutrition, or nervous excita- 
bility, would thus be a solution of the whole problem of life. With every year of physiological advance, however, we seem to get further and further away from any prospect of such a solution. It was only through the prevailing ignorance of physiological facts that the physiologists of the middle of last century imagined that they were approaching a physico-chemical solution of elementary physiological problems. To us Schwann's theory of cell-growth seems almost as crude as Descartes' extraordinary theory of the mechanism of growth and development.

In the physiology of the central nervous system the main progress during the last halfcentury has been in connection with the localisation of function and tracing of paths of physiological connection. Until recently, at least, but little has been done in the direction of a thorough examination of the elementary problems presented by the simplest cases of 'reflex' action. The work of Sherrington and others is now, however, throwing new light on these problems, and it seems quite clear that the old idea of simple and definite 'reflex mechanisms' in the 
central nervous system must be abandoned. In the nervous system physiologists are also faced with the problem presented by the recoveries of functional activity after destruction of centres or nerve paths on which this activity normally depends. In the case of other parts of the body this recovery of function is also evident enough; but in the central nervous system differentiation of function is so complex and definite that recovery of functions stands out as a fact of extraordinary interest and significance. For this phenomenon it is difficult to imagine any physico-chemical explanation.

To sum up, the application to physiology of new physical and chemical methods and discoveries, and the work of generations of highly-trained investigators, have resulted in a vast increase of physiological knowledge, but have also shown with ever-increasing clearness that physico-chemical explanations of elementary physiological processes are as remote as at any time in the past, and that they seem to physiologists of the present time far more remote than they appeared at the middle of last century. 
Probably no competent physiologist will deny this. But, it will be urged, it is only what might be expected that vital mechanism, the product of untold millions of years of natural selection, should be extremely complex; and the fact that it is so affords no real ground for doubting the mechanistic hypothesis. There are many phenomena in inorganic nature which we do not yet understand, but we do not for that reason regard them as having other than physical and chemical causes.

We must now push our examination a stage further. Let us assume that all the delicate and persistent reactions met with in the living body are due to intracellular mechanism produced by natural selection or in any other way, and see whether this assumption will help us to understand the facts. - First of all, let us be clear about what such an assumption implies. Those who have not studied the physiology of the higher and better-known organisms, such as man or some mammal, have often very little conception of the exquisite delicacy of physiological reactions. This delicacy was hardly even suspected in former times. 
DELICACY OF ORGANIC REGULATION 49

Eustachius, who was probably the first to make experiments on secretion by the kidneys, contented himself with taking a dead, and probably decomposing, kidney, and passing through its blood-vessels such liquids as spirits of wine or water, and observing how much of these liquids issued into the ureter! It is only quite recently that we have come to realise the astounding fineness with which the kidneys, respiratory centre, and other parts regulate the composition of the blood.

To illustrate this point I may perhaps refer to a subject which we have recently been investigating at Oxford. We have found that the respiratory centre is so extremely sensitive to any increase or diminution of the partial pressure of carbon dioxide in the blood that a diminution $\mathbf{0 . 2}$ per cent. of an atmosphere, or $1.5 \mathrm{~mm}$. of mercury will cause apncea, while a corresponding increase will double the breathing. The recent researches of Hasselbalch have afforded experimental evidence of what had already seemed very probable-that the stimulus to which the centre responds is the difference in hydrogen 
ion concentration, or acidity, brought about by the very slight deficiency or excess of carbon dioxide. He has also investigated quantitatively the effects on the hydrogen ion concentration of the blood of varying the partial pressure of carbon dioxide. From his results and ours it follows that the hydrogen ion concentration of the blood during rest is extraordinarily constant, and remains so day by day and year by year. As the amount of acid and alkali passing into the blood from the food and other sources is constantly varying, it follows that the regulation of hydrogen ion concentration is mainly brought about by the kidneys. It has been known for long that the urine varies in acidity or alkalinity according to the diet; but Hasselbalch has measured the actual variations in hydrogen ion concentration. Putting together his conclusions and ours, it appears that during ordinary resting conditions the variations in hydrogen ion concentration of the urine are about a hundred thousand times as great as those of the arterial blood.

Thus the kidney epithelial cells react so delicately to variations in hydrogen ion con- 
centration of the blood, that the very smallest variation in the direction of acidity or alkalinity excites them to excrete a liquid which is, relatively speaking, intensely acid or alkaline, the net result being that the normal hydrogen ion concentration of the blood remains practically constant.

When we have such figures before us we realise the marvellous fineness of the regulation by the kidneys and respiratory centre. Physiologists are still so much under the influence of the old gross mechanical theories of secretion that attempts at exact measurements of the delicacy of regulation by the kidneys have hitherto scarcely been made in the case of regulation in other directions, though we have every reason to believe that similar delicacy exists as regards the regulation of the water, salts, and other blood constituents. It is hard to realise that something which looks under the microscope like nothing more than a somewhat indefinite collection of gelatinous material can react, and continue throughout life to react, true as the finest mechanism of highly tempered steel, to the minutest change in its environment. 
We meet with the same delicacy of adjustment in the regulation of such things as bodytemperature, blood-volume, or heat-production. So accurately does the body adjust its consumption of oxygen and of food-material to its energy requirements that it can actually be used, as Rubner found, as a calorimeter; for it substitutes consumption of proteins, carbohydrates, and fats for one another in exact proportion to their energy values as determined with a calorimeter. In Liebig's time this delicate regulation was altogether unknown. It was supposed that any excess of protein simply 'fell a prey' to oxygen, and that if the oxygen percentage of the air was increased, or even if the amount of air breathed was increased, or the barometric pressure was raised, oxidation in the living body would increase, just as in the oxidation of substances outside the body. By accurate measurements of the intake and output of material and energy the true facts as to the rigid accuracy with which metabolism is regulated have gradually been established during the last fifty years.

We must, therefore, in considering the 
mechanistic theory, put aside from our minds all the hazy ideas of former generations as to the structure of living cells being nothing but that of an indefinite 'plasma.' Such ideas belong to the early childhood of physiology. We now know that 'simple protoplasm' exists nowhere, not even among the most primitive protozoa or bacteria. Modern investigation of the complex and intensely specific functional activities of every variety of living organism or cell has relegated the old ideas, derived from mere microscopic examination, to oblivion. What the mechanistic theory must assume in the case of an organism such as man is a vast assemblage of the most intricate and delicately adjusted cell-mechanisms, each mechanism being so constituted as to keep itself in working order year after year, and in exact co-ordination with the working of the millions of other cell-mechanisms which make up the whole organism.

This assumption is surely one which taxes scientific imagination to the utmost, but let us make it and continue the argument. We have now to imagine the mechanism of repro- 


\section{CRITICISM OF MECHANISTIC THEORY}

duction and heredity. This vast organisation of cell-mechanisms has all been developed from a single cell, itself the product of the union of two cells-an ovum and a spermatozoon; and we have every reason to believe that the hereditary characters, which are derived through both cells, are carried in the two nuclei which unite to form the nucleus of the fertilised germ-cell. On the mechanistic theory this nucleus must carry within its substance a mechanism which by reaction with the environment not only produces the millions of complex and delicately balanced mechanisms which constitute the adult organism, but provides for their orderly arrangement into tissues and organs, and for their orderly development in a certain perfectly specific manner.

The mind recoils from such a stupendous conception; but let us follow the argument further. In the previous lecture I gave such an account of heredity as is usually given from the mechanistic standpoint. It needs very little consideration to see that this account consisted of little more than empty words. The germ-plasm was supposed to be 
nothing more than a collection of material of a certain composition, and capable, in a suitable environment, of indefinite quantitative increase or growth. Parent and offspring were supposed to be similar because they had both sprung from germ-plasm of the same composition. This germ-plasm could be added to, divided, or mixed with other germ-plasm in sexual reproduction, just as if it were so much treacle.

It seems perfectly clear that germ-plasm of so simple a character as this could by itself furnish no explanation whatever of the development from it of the adult organism with all its enormous complication and absolute definiteness of structure. If the germ-plasm were so simple, the complication and definiteness would have to be attributed to its environment: whereas all the evidence points to the nuclear germ-plasm as the essential carrier of hereditary characters. We are thus compelled, on the mechanistic hypothesis, to attribute to the germ-plasm, or germinal nuclear substance, a structure so arranged that in presence of suitable pabulum and stimuli it produces the whole of the vast and 
definitely ordered assemblage of mechanisms existing in the adult organism. Such a structure must be absolutely definite and inconceivably complex. There is no escape from this assumption; and to speak of 'plasma' when we mean such a structure is clearly absurd.

This nuclear structure or mechanism must, according to the mechanistic theory, have been formed within a very short period by the union of two others-a male and a female one. How two such mechanisms could combine to form one is entirely unintelligible, and the observed details of the process tend only to make it, if possible, more unintelligible. When we trace each nuclear mechanism backwards we find ourselves obliged to admit that it has been formed by division from a pre-existing nuclear mechanism, and this from pre-existing nuclear mechanisms through millions of cellgenerations. We are thus forced to the admission that the germ-plasm is not only a structure or mechanism of inconceivable complexity, but that this structure is capable of dividing itself to an absolutely 
indefinite extent and yet retaining its original structure.

We might, perhaps, get over the difficulty for a generation or two of cells, by assuming that the germ-plasm contains, not one, but several nuclear mechanisms, and that only one of these mechanisms comes into play at each reproduction, others being left to form the germ-plasm of the next generation, or otherwise to provide for emergencies. As a matter of fact, a theory of this kind has been put forward in order to account for the fact that, as has been shown so clearly by Driesch and others, not only the germ-cells, but also other cells in the developing embryo, or even in the adult organism, may, on occasion, give rise to the reproduction of a whole organism. It has been supposed that parts of the original germ-plasm, or, in plain English, nuclear mechanisms capable of giving rise to the reproduction of a whole organism, may and do pass into ordinary somatic cells, as well as into the direct line of future sexual reproductive cells.

This far-fetched hypothesis only makes matters worse for the mechanistic theory of 


\section{CRI'TICISM OF MECHANISTIC THEORY}

heredity ; for we have to account, not for only one, but for a large number of stupendously complex reproductive mechanisms within the original germ-plasm, and for their endless division and multiplication. The real difficulty for the mechanistic theory is that we are forced, on the one hand, to postulate that the germ-plasm is a mechanism of enormous complexity and definiteness, and, on the other, that this mechanism, in spite of its absolute definiteness and complexity, can divide and combine with other similar mechanisms, and can do so to an absolutely indefinite extent without alteration of its structure. On the one hand we have to postulate absolute definiteness of structure, and on the other absolute indefiniteness.

'There is no need to push the analysis further. The mechanistic theory of heredity is not merely unproven, it is impossible. It involves such absurdities that no intelligent person who has thoroughly realised its meaning and implications can continue to hold it.

It may, perhaps, be argued that although a mechanistic theory of reproduction appears 
to be impossible, this need not affect the practical value of the mechanistic theory in biology. In ultimate analysis the ordinary working conceptions of physics and chemistry present great difficulties; but no one doubts, for example, the practical value of the hypotheses of mass, energy, atoms, and molecules. Similarly, there may be ultimate difficulties about a mechanistic theory of life, and yet the practical value of this theory may remain.

There is certainly some truth in this argument. We often treat a living organism, or some portion of it, as if it were nothing but a collection of ordinary matter, or a machine actuated by the ordinary forces of nature. As will be pointed out more fully below, this mode of treatment is sometimes the best that is practicable, and its value cannot be doubted. In so treating the facts we are, however, leaving out of account almost all those phenomena which are apparently specific to living organisms, and with which biology mainly deals. In actual fact the failure of the mechanistic theory of reproduction cuts deep into our conceptions of almost every 
detail of biological fact and investigation. Biology deals at every point with phenomena which, when we examine them, can be resolved into metabolic phenomena-exchange of material and energy, as exemplified in growth, development, maintenance, secretion and absorption, respiration, gross movements in response to stimuli, and other excitatory processes. Now metabolism is itself a constant process of breaking down and reproduction of what is living. There is no reason for separating the reproduction of a whole organism from the constant reproduction of parts of it in ordinary metabolic process. Hence our conception of heredity involves every part of biology; and if we cannot frame a mechanistic theory of heredity we are equally at a loss in connection with the ordinary phenomena of metabolism, and we have no right to use mechanistic hypotheses in connection with these phenomena. We have also seen already that the ascertained facts do not in any case point to mechanistic theories of the ordinary activities with which biology deals.

As a physiologist I can see no use for 
the hypothesis that life, as a whole, is a mechanical process. This theory does not help me in my work; and indeed I think it now hinders very seriously the progress of physiology. I should as soon go back to the mythology of our Saxon forefathers as to the mechanistic physiology.

Although the mechanistic theory of life will soon become a matter of past history, there can be no doubt that it has filled an extremely valuable part in the development of physiology. Again and again mechanical theories of one sort or another have served as temporary working hypotheses round which experimental investigation has centred in physiology. This has been as true of the grosser mechanical hypotheses of the seventeenth century as of the more refined physical and chemical hypotheses of later times. The merit of these hypotheses has been that they were capable of either verification or disproof, whereas the vitalistic theories have been incapable of being experimentally tested.

Let us try to see why the latter has been the case. The vital force was conceived as something acting 'from the blue' on ordinary 
matter, and yet as not acted on itself. Its presence could only be verified through the failure of physical and chemical explanation of certain very striking phenomena, namely the development and maintenance of a certain specific structure and certain specific activities. In so far as any fact connected with life could be explained on physical and chemical grounds the vitalists were at one with the mechanists.

I In so far as physico-chemical explanation failed they attributed the phenomena to the intervention of the 'vital force.' Thus their dualistic working hypothesis fitted the facts in whatever way they turned out, so that the stimulus afforded by one definite hypothesis, which could be either verified or disproved, was absent. But as they admitted the hypotheses of physics and chemistry with regard to the material and atomic constitution of the universe, and based all their observations and methods on these assumptions, the natural consequence was that in matters of experimental detail they always found themselves dealing either with what appeared to be physical and chemical phenomena or with something unintelligible. 
In detail, therefore, the sphere of action of the 'vital force' was a dim and misty sphere of unintelligibility - a purely negative sphere. So far as anything definite could be traced on the confines of this sphere it was something physical or chemical, and beyond this was indefinite mist. Where and how the ' vital force' acted on the atoms or molecules, or what exactly became of them, no one could say; but out of the mist they seemed to appear again, once more in the form of atoms and molecules obeying physical and chemical laws, but ordered in such a specific and unmistakable manner as to indicate that within the sphere of indefinite mist some mysterious factor was at work. As, however, the only definite detail was physical and chemical detail, the mechanists were left in possession of all that could be positively investigated in detail.

The mechanists have contended that the misty sphere is only the mist of our ignorance of the physical and chemical conditions, and that year by year this mist is being gradually dispelled by the advance of physiological investigation. We have seen already that 
this is a complete illusion. The advance of investigation has only served to make the misty sphere more evident; and not only does it exist, but there is not the remotest chance, as we have just seen, that physical or chemical investigation will ever dispel the mist. The phenomena of life are of such a nature that no physical or chemical explanation of them is remotely conceivable.

Let us try to get to grips with this matter. What is the real cause of the helpless position in which biology finds herself? 'The mechanistic hypothesis has been the only one of the two which seemed inherently capable of helping us positively in the details of biological investigation; and yet this hypothesis is unmistakably a failure in relation to biological investigation as a whole; and the vitalistic theory, if one can call it a theory, is only a way of registering this failure, and does not help us to a real understanding.

The main outstanding fact is that the mechanistic account of the universe breaks down completely in connection with the phenomena of life. Whether it is not also insufficient in connection with phenomena 
outside what we at present regard as life is a further question which need not be discussed at present. When any hypothesis fails to correspond with facts it is the hypothesis which needs reconsideration. In the next lecture the physico-chemical hypothesis with regard to our experience generally must first be examined, after which we must consider whether no other hypothesis will fit the facts. It may be that the practical failure of vitalism has depended on the fact that the vitalists have accepted without criticism the physico-chemical account of our experience, and have thus placed themselves in a position in which they are powerless to help biological investigation. 


\section{LECTURE III}

BIOLOGY AND THE PHYSICAL SCIENCES

Ar the end of the last lecture we were led up to the question as to how far the interpretation assumed by the physical sciences in their account of the visible and sensible universe is valid. This is evidently a very wide question, involving far-reaching philosophical discussion. Yet the reason why such a discussion cannot be shirked is evident. We found that in the case of life the facts are inconsistent with the physical and chemical account of phenomena. We, therefore, cannot adopt the attitude that whatever may be the ultimate truth about the universe the ordinary working hypotheses of physics and chemistry are sufficient for the immediate purposes of our work as physiologists. We must probe more deeply.

At the present time there is a widespread 66 


\section{PHILOSOPHY AND PHYSICAL REALITY 67}

prejudice against philosophical or 'metaphysical ' discussions. It is asserted, for instance, that system replaces system in the history of philosophy, and no abiding truth is arrived at. The efforts of philosophers are thus vain, and practical men would do well to disregard completely all metaphysical speculation.

Such teaching is unworthy of every tradition which has helped to raise us from the level of primitive savages. Even if it were true that philosophical speculation has hitherto led to no definite result, we should not be men if we gave up the quest after truth. It is only, however, a shallow and ignorant mind that sees in the history of philosophy nothing but a series of systems, each as bad or as good as the other, and succeeding one another like the 'turns' in a music-hall entertainment. The progress of philosophy has been just as continuous as the progress of science, and the history of philosophy appears to be a meaningless succession of systems to those only who have never taken the trouble to understand them.

To philosophers the meaning of that appearance of physical reality with which we 
are so familiar has been a constant subject of investigation, and we must consider as well as we can what light they have thrown on the particular problem before us. We must, therefore, try to trace the reasoning which, in its successive developments, has guided them.

When we regard the conception of the visible and tangible universe as it is presented to us by the physical sciences we find that it not only stands the most searching laboratory tests, but that it also stands the tests of practical experience of a very wide kind. The engineer, the manufacturer, the navigator, the soldier, the lawyer, can apparently rely upon it absolutely. But philosophy points out that \} if it corresponds to absolute reality it must be consistent with the rohole of our experience; and first and foremost it must be consistent with our own conscious relations to it, which have, after all, been entirely left out in the laboratory and other tests.

At first it may seem simple enough to say that we are conscious of the physical world. It is there, plainly before us. But then comes the reflection that the appearance can only be transmitted to us through our sense organs 
and sensory nerves. All that we immediately perceive can only be sensory disturbances of some kind, from which we infer the existence of the physical reality outside. This is a necessary, but also a fatal admission : for what right have we to draw such an inference? Absolutely none, as Bishop Berkeley first pointed out. We have no right even to call our sensations impressions, or to regard ourselves as anything more than a stream of sensations. The appearance of a sensible world, with our bodies present in it, can be nothing but an appearance due to the manner in which the sensations group themselves. The appearance of substantiality or of cause and effect can be due to nothing else but the mysterious fact that certain sensations are associated together or follow one another in a certain order. Such was the reasoning of David Hume; and his inferences follow inevitably if we start with the provisional assumption that the physical world as science represents it to us has absolute reality. If it has, then we cannot possibly know it ; and all our supposed knowledge is nothing but the illusion which Hume described. 
There is no flaw in the reasoning of Berkeley and Hume, absurd as may seem the conclusions which they reached. The flaw is in the premises, and particularly in the assumption from which the reasoning originally started, that the world is something self-existent.and outside us, as physical science appears to teach. This assumption simply destroys itself, leaving nothing but the sceptical conclusions of Hume.

How long will it be till the world, and particularly the scientific world, begins to take in the significance of David Hume's reasoning? His body has lain quiet at the foot of the Calton Hill in Edinburgh for nearly a hundred and forty years; but the old ideas which he finally showed to be untenable are still popularly accepted, just as if he had never lived. To those who imagine that the secrets of our existence are likely to be revealed in, say, the latest discoveries in colloid chemistry, I would commend a careful perusal of Hume's Treatise of Human Nature.

Whether we take the ordinary popular view, as taught by the theologians, that the 
soul is a non-material entity situated during life within a material body in a material world, or else adopt the mechanistic theory that there is no soul, but only a series of 'states of consciousness' lighted up somehow or other within a material brain, we cannot escape Hume's destructive criticism. This criticism destroys utterly the assumption of a universe of self-existent things.

But the appearance of knowledge of our universe and all that it contains does certainly exist and must be accounted for. The task of accounting for it was taken up by Immanuel Kant, who carried us far beyond Hume.

Kant did not satisfy himself with Hume's account of the data of consciousness as a stream of isolated impressions or sensations, cohering or associating themselves with one another in a manner of which we can give no ultimate account. He proceeded to examine carefully the nature of sensation or perception. One thing which he found was that sensations never do exist in isolation from one another, but that each carries with it a reference to other sensations. A sensation, if it is distinguishable at all, is here and now. 
This means that it is given in relation to past, future, and co-existent states of consciousness which are indissolubly united with one another. Moreover, each distinguishable element in experience bears with it its relation to the others in a certain order. Were there no such definite relations of sequence and spatial interconnection there could be no perception or experience at all: the 'hereness' and 'nowness' of each element in experience would be impossible. Hence spatial and temporal relations, causal sequence, substantiality, and the other general ideas by the existence of which our experience is ordered, are all given to us in the simplest elements of experience. The supposed possibility of analysing our perceptions into elements consisting of 'simple' unrelated sensations or ' states of consciousness,' is an illusion. There are no such things as unrelated sensations.

Now this, of course, does not imply that the whole visible universe is given to us as an intelligibly connected system as soon as we open our eyes. It does mean, however, that from the beginning the outlines of such a system are present, however dim and indefinite 
the details may be. It means also that between ourselves and the world round us, and between the various things which we find in the world, there is no ultimate separateness of existence such as seems to be assumed in the ordinary physical conception of the world. All are parts of one inseparable whole.

This is a conclusion of such stupendous and far-reaching import that it may need centuries for the world to take it in and even dimly realise its implications, and where it leads us to. Sooner or later, however, it will be realised that the materialism of the nineteenth century has been nothing but an insignificant eddy in the stream of human progress. In Kant's writings his thought was evidently trammelled by the difficulty of realising how great a leap forward he was making. Hume's scepticism had not completely done its work in his mind, for he still postulates the existence of a so-called noumenal world of things-inthemselves which are the unknowable cause of the constant newness and variety in our experience. He also retains the idea of finite individual minds, each armed, as it were, with general ideas or 'categories' which convert 
into the orderly system of our experience the impressions caused by the noumenal reality. His immediate successors pointed out that there was no reason left for assuming the existence of things-in-themselves outside of us. 'These supposed existences are nothing but the ghosts of the world of independently existing matter which Hume had shown to be non-existent. The supposed separately existing finite minds are also not proof against Hume's criticism. We must account otherwise for all the variety and 'contingency' of our universe. Both the external world of things and the spiritual world of persons have their existence, somehow or other, in only one Supreme Existence. In the efforts to show in detail how this is so the philosophical movement initiated by Kant exhausted itself for the time; but we shall have occasion to return later to these efforts.

We must now look somewhat more closely at Kant's account of how the sensible world comes to appear to us as it does, and what bearing his conclusions, and those of his successors, have on the great biological problem which is the main subject of these lectures. 
Kant enumerated definitely the 'categories' or general ideas under which he believed that our perceptions are ordered. This list seems very artificial, and is based on the old formal logic, but it includes the ideas of substance, cause and effect, and reciprocal action-the ideas of the physics of Kant's time. He himself, it may be remarked, was a physicist and mathematician of no mean repute. The list limits perception to the perception of a purely physical world, such as the physical sciences described, and he had no special category for living organisms. On Kantian principles, therefore, a living organism can only be perceived as a material structure or mechanism. In this respect, Kant was at one with the mechanistic school of biologists. For him, however, the reason why we must perceive organisms as mechanisms is not because they, in themselves, are mechanisms, but because the mind is so constituted that it can only perceive them as mechanisms.

Kant's successor, Hegel, pointed out that his list of categories was incomplete in various directions: also that a special category or categories ought to be added 
for organic life, as the idea of life is one of the fundamental ideas. There is no reason why a category or general conception of life should not be just as much constitutive of our experience as the category of substance. Here, therefore, we have a possible way out of our difficulties with the mechanistic theory of life. In trying to reduce life to physical and chemical mechanism we are perhaps in some way confusing two different categories. Kant's general philosophical conclusions have in any case thrown a quite new light on our conceptions of the physical world, and have taught us that the validity of these conceptions is of a very different nature from what was previously believed. It may be that just as we cannot base physics on the purely mathematical conceptions of extension, so we cannot base biology on the purely physical conceptions of matter and energy. With these possibilities in mind let us return to a discussion of the facts which biological investigation discloses.

+ What we have first to ask is whether, as a matter of fact, we habitually use, in dealing 
with the phenomena of life, a fundamental conception or working hypothesis which is different from the fundamental conceptions of the physical sciences, and cannot be reduced to them. The question, for the moment, is not whether we are justified in using such a conception, but whether we actually do use it. When this question is clearly realised there is, it seems to me, but one answer to it, and that in the affirmative. In dealing with life we not only use a whole series of special terms, but these terms appear to belong to a specific general conception which is never made use of in the physical sciences.

Life manifests itself in two ways-as structure and as activity. But we also recognisea biologist feels it in his very bones-that this is living structure and living activity. Each part of the structure not only bears a more or less definite spatial relation to the other parts, but it is actively maintained in that relation. 'The structure is thus in itself the expression of the activity, and the ceaseless metabolic activity of which visible structure is the sensuous expression forms one department of 
physiological study-that of nutrition. But the more closely living activity in general is examined, the more clear does it become that all living activity is structural or metabolic activity, either directly or indirectly. The changes in the retina when light falls upon it are metabolic or structural activities. The same is true of the activities of nerve cells, muscle cells, gland cells, or any other living cells; and the gross visible movements of the body, no less than its gross visible structure, are but the outer sign of metabolic activity.

The body can also be affected mechanically or chemically by influences from without; but effects so produced are of not the slightest interest to a biologist, except in so far as they may be connected with living activity.

The living structure is evidently organised : that is to say every part of it bears a definite relation to every other part. As, however, the structure is the outcome of metabolic activity, it follows that the metabolic activity of the living body is also organised, every aspect of it bearing a definite relation to 
every other aspect. That this is actually so has become more and more clear with the advance of physiology, particularly in recent times. The fundamental mistake of the mechanistic physiologists of the middle of last century was that they completely failed to realise this. Such processes as secretion, absorption, growth, nervous excitation, muscular contraction, were treated as if each was an isolable physical or chemical process, instead of being what it is, one side of a many-sided metabolic activity, of which the different sides are indissolubly associated.

The relation of the living organism to its environment is no less peculiar and specific than the relationship of the internal parts and activities of the organism itself. Between organism and environment a constant active exchange is going on. But this exchange, in so far as it has any physiological significance, is always determined in relation to the rest of the living activity of the organism. Whether material is to be taken up or given off, whether and to what extent the organism is to respond to any 'stimulus,' all this is determined in relation to the life of the 
organism as a whole. The living body and its physiological environment form an organic whole, the parts of which cannot be understood in separation from one another.

Our ordinary language as applied to life corresponds with these characteristics. We naturally speak of a living organism as an autonomous active whole, and think of it as such. The idea of its being a mechanism made up of separable parts, and actuated by external causes, is wholly unnatural to us, and becomes more and more unnatural the more we know about organisms.

The concept we are using is radically different from any physical concept: for in conceiving what is living we do not separate between matter or structure and its activity. The structure itself is conceived as activeas alive.

But the objection may be raised that this is only a loose and inaccurate mode of thinking and expression: for we know that the living substance consists of nothing but matter, though we do not yet know in what exact form the atoms or molecules are combined. This, it must be pointed out clearly, is simply 
to beg the whole question. It was the complete and hopeless failure of the material conception of a living organism that led to our present inquiry. We cannot admit that the living 'substance' is material. It is the very existence of matter as such that is in question-the adequacy of the concept ' matter' to express the phenomenon we are considering. Let us make no mistake as to what we are really discussing. We have parted company once and for all with the mechanistic philosophy-the notion of a real and selfexistent material universe; and we must remember where we now are.

What we have found is that the conception of the living organism is in common and ordinary use, and differs radically from any physical conception. We have also seen that there is no philosophical reason for rejecting this conception. There is no $a$ priori reason why we should not, if it helps us, take it as the fundamental conception for biology, just as the physicist takes the conceptions of matter and energy as fundamental for physics.

Before going further we must consider a 
preliminary objection. Whatever the nature of the actually living parts of an organism may be, all that we can do in investigating them, it may be pointed out, is to observe and measure the physical and chemical changes resulting from their activity. We can measure the shortening of a muscle, the pull it produces, the oxygen it absorbs, the electrical changes which accompany its excitation. All these are physical and chemical changes, however; and the whole of physiology consists, and can only consist, of such observations and measurements. It must, therefore, from the very nature of its data, be a physical and chemical science in so far as it is a science at all.

The reply to this is that apparent physical and chemical changes are the signs or sensuous data which point to the underlying living activity. Just as the physicist has no direct detailed knowledge of matter, but infers its properties and measures its amount from various sensuous data, so the physiologist infers the nature and activities of a living organism from sensuous data. But to the physiologist the outward appearances of 
physical and chemical change are the sensuous data, by bringing which into relation with his guiding idea he arrives at physiological knowledge; and what he sees behind the appearances of changes in form, electrical changes, absorption of oxygen, and all the other outward signs of muscular activity is the metabolic activity of the living muscle-cells.

If we assume that the conception of the living organism is the fundamental conception of biology, it is clear that the aim of biology differs entirely from what it would be if the mechanistic theory were accepted. All attempts to trace the ultimate mechanism of life must be given up as meaningless. The aim of biology becomes a very different oneto trace in increasing detail, and with increasing clearness, the organic determination which the ground conception postulates. The bodily processes-for instance, the apparent mechanical or chemical processes of movement of the limbs, of breathing, of circulation, of digestive changes, of the taking up and giving off of various forms of matter and energybecome nothing but the expression of organic activity. Their maintenance and working 
during life are only phases of the organic determination which is the key to all the phenomena of life. They must be looked at from the physiological or biological standpoint, and not merely from that of the physical sciences. The details of bodily structure must likewise be interpreted as the expression of organic determination.

Now it seems to me that the actual progress of physiology, and of biology generally, corresponds exactly with the increasing realisation of this aim. It has already been shown that in tracing the history of physiology we find that on the whole there has been no apparent progress whatsoever towards the mechanistic goal. On the other hand it is perfectly plain that there has been enormous progress, not merely in ascertaining isolated facts, but in tracing organic determination in every detail of bodily structure and physiological activity.

To illustrate this conclusion in detail it would be necessary to present to you, not a single lecture, but a whole text-book of physiology. I shall, however, try to give a single illustration by tracing roughly part of 
the progress of our knowledge in relation to the regulation of breathing.

From the earliest times it was of course known that in all the higher animals breathing is an essential part of organic activity, as mechanical stoppage of the breathing causes rapid death. Very little further was known, however, until the time of Black, Priestley, and Lavoisier, although Mayow, the fundamental importance of whose work was not at the time appreciated, had in reality come very close to modern ideas. With a single flash the whole subject was illuminated by the definite discovery of oxygen and carbon dioxide and their relation to respiration. Henceforth we knew that the necessity for breathing, and the regulation of breathing, is bound up with the necessity for absorbing oxygen and giving off carbon dioxide. Breathing is of fundamental physiological importance, because the consumption of oxygen and removal of carbon dioxide are fundamental organic activities in animals.

Assuming that an organism is an organism, and not a mere machine, we should expect to find that these activities are organiF 2 
cally determined-determined as in definite relation to the whole functional and structural activities of the organism, and not merely dependent on specific and one-sided conditions, such as the abundance of oxygen in the inspired air, or its freedom from carbon dioxide, or some mechanical action of the nervous system, unrelated to the central organic determination.

Misled by mechanistic conceptions of life, various physiologists have, as a matter of fact, put forward one-sided theories of this kind, and they have invariably turned out to be wrong. As an example we may take the theory that owing to the structure of the respiratory centre, and the properties of the afferent nerves coming to it from the lungs, breathing goes on, under ordinary conditions, automatically and without reference to the removal of carbon dioxide or intake of oxygen. It was believed that as distention of the lungs excites fibres in the vagus-nerve which inhibit inspiration, and collapse of the lung correspondingly excites fibres which excite inspiration, normal breathing is regulated by this mechanism, though the centre also responds to any 
unusual want of oxygen or excess of carbon dioxide in the blood.

Now it seemed extremely improbable that such a theory could be correct; since living organisms do not regulate their affairs in this mechanical manner. Thus guided, we reinvestigated the whole question in the Oxford Physiological Laboratory, and found that as a matter of fact the breathing is, under normal conditions, so regulated in man as to respond with almost incredible exactness to the slightest variation in the output of carbon dioxide or partial pressure of carbon dioxide in the alveolar air. The vagus nerve-fibres play no part in the main regulation, to which their influence is only subsidiary, though not unimportant.

Under ordinary conditions the constancy in the pressure of carbon dioxide in the lung alveoli provides for the supply of oxygen to the lungs and blood; but quite evidently the breathing is, under abnormal conditions, regulated also in direct relation to the oxygen supply ; and the action of the lung epithelium, the concentration of hæmoglobin in the blood, and the mode in which oxyhæmoglobin is 
dissociated in the blood, play an important part in helping this regulation.

The idea which gives unity and coherence to the whole of the physiology of respiration is that of the organic determination of the phenomena. The same idea has to a greater or less extent already given, or is in process of giving, unity and coherence to the phenomena of nutrition, secretion, and circulation. It is an idea which guides us at every turn in physiological work, and constantly suggests new lines of investigation. To leave it out of account in physiology, or to treat it as a mere 'heuristic principle' of very uncertain value, seems to me about as foolish as it would be to reject the idea of mass in chemistry, and retain the phlogiston theory, as Priestley and Cavendish actually did till their deaths. By regarding the structure and activities of a living organism as the expression of organic unity we arm ourselves with a theory which is just as useful in biology as the idea of mass in chemistry. Neither the idea of mass nor that of organism will enable us to predict everything in the chemical and biological worlds respectively, but they both help us 


\section{DEFECTS OF CURRENT PHYSIOLOGY 89}

enormously in reducing our observations to order.

When we turn from actual physiological investigation to the current text-books on the subject we are confronted by the fact that in accordance with prevalent philosophical beliefs among physiologists, these books are mainly written from what is essentially a mechanistic standpoint, and follow more or less closely the general plan of Ludwig's famous textbook of sixty years ago. An account is given of the physical structure and chemical materials found in the body and its environment, and this account is combined with an analysis of how the whole works when the various elements so distinguished are brought into relation with one another during life.

In this general plan there is absolutely no place left for the living organism as such. We find, moreover, that the various ' mechanisms'. to which the headings of the various chapters correspond-the mechanisms of neuro-muscular activity, nutrition, secretion, absorption, etc.-exist, for both reader and author, only as ideals on paper; and at the end the reader is perhaps inclined to . become a vitalist-per- 
haps not. The author, too, may probably have displayed suspicious vitalistic tendencies. One thing, however, is pretty clear-that the information supplied with regard to the central or 'elementary' problems of physiology is often so vague as to be of little apparent practical importance. The practical physiological information which a student of medicine needs and uses is to a large extent only picked up afterwards at the bedside or in the study of experimental pathology.

What is the reason for this defect in physiological teaching? One might at first suppose that whatever general theoretical opinions might be held by a physiological teacher, yet the facts of the science itself must be the same, and that in teaching the facts, as undoubtedly he does to the best of his ability, he must be doing all that is possible. But here comes in the question, what facts? The facts recorded by physiologists are absolutely indefinite in number, and only the more important ones can be taught. Hence, in accordance with the general plan just alluded to, only those facts which bear on the 'mechanisms' of the 


\section{DEFECTS OF CURREN'T PHYSIOLOGY 91}

various physiological processes can be taught. If, for instance, we are teaching the physiology of the kidneys, we must teach the main facts bearing on the possible mechanism of secretion of urine. We must thus discuss the possible influence of filtration, diffusion, etc., in the process, leaving out of account all details which are irrelevant to this discussion; and when at the end it turns out that the essential mechanism of secretion is quite unknown there is nothing further to do than pass on to the next subject. Actually it is known that, mechanism or no mechanism, the kidney fulfils its functions of regulating the composition of the blood, and that it does so with marvellous delicacy; but facts relating to this do not fit into the plan of exposition of the subject, and have too much of a smack of old-fashioned teleology about them. Hence they are ignored completely, or scarcely touched upon.

It is the same with circulation, respiration, and every other part of physiological knowledge. The fact that the body lives as a whole, each organ or part fulfilling its proper functions and adapting itself to every change, 
is scarcely touched upon, while a vast mass of unrelated and unassimilable mechanical detail is carefully recorded and described.

The fault evidently lies in the general plan of exposition. This plan does not fit the facts to be described. The living body is a living organism, and physiology must treat it as such, or else submit to the reproach of being a complete failure. The attempt to treat physiology on the principles so clearly laid down in Ludwig's Introduction to his text-book is as wide of the mark as would be an attempt to treat painting and sculpture on the basis of a mere knowledge of the chemistry and physics of paint and marble.

Teaching and investigation must begin, continue, and end with the presupposition that the body is a living organism, which must be seen as a whole if it is to be seen at all. To shut our eyes to the central fact of living organic existence is to shut our eyes to physiology itself, and to biology generally. It does not matter what aspect, or what portion of physiology or biology we are studying: we are always face to face with living organisms as wholes or parts of 
organic wholes. The divisions of the subject are due, either to the particular organisms studied, or to the particular methods of investigation which we happen to be capable of using to advantage. In so far as we are in earnest with the work, and are not blinded by wrong theories, we are always, both in physiological and morphological investigation, studying an organism as a whole.

In the case of the higher organisms we are of course dealing with a compound organism; and we have all shades between highly organised compound organisms and more or less indefinite collective organisms such as a colony or a whole species. In these organisms there is constant active maintenance, constant renewal, constant breaking down and reproduction of the living structure; and this is of the very essence of our conception of life. Reproduction is not in itself a problem, but an axiom; for all living structure is active structure; and it lives in actively maintaining itself and reproducing its structure.

In normal reproduction and death, and in 
all instinctive social activity, the individual organism shows itself to be more than a mere individual: it belongs to a wider organic whole. Death is certainly not the mere mechanical wearing out of the organic machine: for the organism, as we have already seen, is no machine. Not only in reproducing itself as a whole, but also in the metabolic processes by which it is changing its substance at every moment, does it flout such a conception. So far as we can at present understand the matter, the physiology of death, and that of reproductive and social activity in all their wide ramifications, belong to the physiology of the species. The individual organism, like the individual cell in a complex organism, belongs to a wider organic whole, apart from which much of its life is unintelligible.

It may be argued that in postulating the existence of such a thing as a living organism as a specific entity we are abandoning all attempt at explanation. We are certainly abandoning the attempt at causal explanation; but in doing so we are only abandoning the philosophical ideas which have already 
been shown to be defective and irreconcilable with experience in relation to the phenomena of life. This part of our experience implies the conception of life. By a process of abstraction from the distinctive facts of life we can, it is true, regard organisms as simply so much matter, with so much energy passing through them. If they had turned out to be capable of interpretation as mechanisms this would have been no abstraction, but a correct way of regarding them. But since they are what they are, their structure must be regarded as living structure, and their activity as living activity, both structure and activity being the expression of an organic and indivisible whole. The ideas of matter and energy are nothing but ideas; and in the case of life these ideas are united and transformed in the idea of the living organism.

This leads us back to the philosophical conclusions of Kant and his successors. For Kant the categories or general conceptions under which our experience is ordered were so many separate conceptions unrelated to one another. We might roughly compare 
them to the chemical elements as they appeared to science before the discovery of the periodic law and the breaking down and probable building up of elements. Hegel pointed out that not only was Kant's list of categories incomplete, but that the categories bear a natural relation to one another, the lower being the more abstract or empty general conceptions furthest from reality, and the higher being the more concrete and definite ones nearest to reality. If, for instance, we regarded our experience as consisting of nothing but qualitatively different data we should be using an empty and abstract category. If we regarded it as a world of substances acting on one another we should be seeing it under a much less empty category, and the qualities and their changes would now appear as the qualities and changes of substances. If we regarded it as a world of living organisms we should be using a still higher and less empty category ; for substance, quality, and activity would now be united in a conception out of which they all issue, the activity being no longer regarded as an accident of the 
substance or matter, and quality being no longer a mysterious attribute of substance.

It is evident that we cannot apply this or that category at will. Specific categories seem, as it were, to be embodied in all that we experience. By no mere arbitrary process of thought can I make a piece of stone into a living organism or vice versa. I can, however, deliberately abstract from what the living organism really is, and regard it as simply a material system. This, indeed, is what the mechanistic theory of life invites me to do. I can also abstract from what the stone is, and regard it as simply a patch of colour. This, or something like this, was what Berkeley and Hume invited us to do, pointing out that the stone, as a substance outside us, is only a metaphysical product of our imagination, and that all that is really experienced is a patch of colour. But, as Kant showed in principle, we cannot thus divest our world of its meaning: we cannot reduce higher to lower categories, and thus explain the higher away: we find that the higher categories are embodied in the very texture of our experience. 


\section{BIOLOGY AND PHYSICAL SCIENCES}

When we examine the process of knowledge itself we find that it is a progressive defining of our experience in terms of fundamental conceptions or categories: also a gradual passing from lower, more abstract or indefinite conceptions to higher, more concrete or definite ones. 'This is the course of all scientific investigation. It is only with infinite travail and pains that our experience gradually defines itself in terms of higher and more definite conceptions. A living organism is not given to us complete in thought all at once: it only gradually reveals itself more and more definitely in the course of long and arduous biological investigation. It is the same on a lower plane for the physical world, or for the mathematical world of abstract form and quantitative relations. But from the very nature of the categories or fundamental conceptions themselves all true knowledge must be a gradual revelation of the lower or more abstract in terms of the higher or more concrete aspects of reality; and as the conception of organism is a higher and more concrete conception than that of matter and energy, science must ultimately aim at 
gradually interpreting the physical world of matter and energy in terms of the biological conception of organism. No lower claim than this will satisfy the ideals of biological investigation : of this we may be well assured.

At the time of Kant and his immediate successors biology had hardly begun to be conscious of her strength. Living organisms seemed, as it were, to be at the best only dotted about here and there in the midst of a totally foreign physical universe. Kant assigned to them a very doubtful place in his philosophy, and Hegel in his Philosophy of Nature represented Nature as a sort of waste in which any and every kind of existence is strewed about indiscriminately - a conception repugnant to true science. Meanwhile the advance of the natural sciences has profoundly changed our outlook on Nature. First and foremost we have come to realise the fact of evolution. The true significance of this fact is a very different one from what is still very generally supposed. At first evolution appeared in popular thought, embodied, for instance, in the writings of Herbert Spencer, as a derivation of the 


\section{BIOLOGY AND PHYSICAL SCIENCES}

organic from the inorganic. We have seen already, however, that, evolution or no evolution, there is not the remotest possibility of deriving the organic from the inorganic. Evolution, therefore, takes on a very different significance. In tracing life back and back towards what appears at first to be the inorganic we are not seeking to reduce the organic to the inorganic, but the inorganic to the organic. The apparently indefinite microscopical aggregations of formless colloid material -'sarcode' or 'protoplasm'-which were at first taken for the origins of life from the inorganic, have gradually turned out to be definite living organisms. But biology will not stop at these: for they must have been evolved from something more primitive. She will gradually push her advance victoriously further and further into the domain of the apparently inorganic.

The premonitory signs of this advance are not lacking. For nearly a century-since the days of John Dalton-the chemical atom was the ultimate term of physical and chemical investigation. The world seemed to be resolved into a world of atoms, in 
which, as du Bois Reymond pointed out, there was no place for life in any such sense as that which I have endeavoured to depict in this lecture. Recent discoveries in physics and chemistry have, however, completely shattered this conception, and with it that of matter and energy. We now see physicists and chemists groping after biological ideas. No one can yet tell what conceptions will emerge from the ruins of the atomic theory; but it is at least evident that the extension of biological conceptions to the whole of Nature may be much nearer than seemed conceivable even a few years ago. When the day of that extension comes the physical and chemical world as we now conceive it-the world of atoms and energy-will be recognised as nothing but an appearance, though for practical purposes it will still remain very useful. It will stand fully confessed as a world of abstractions like that of the pure mathematicians. Meanwhile it is already a world of abstractions to the biologist who has faith in the principle of evolution and also in the fundamental conception of the living organism. 
To one point with reference to the biological conception of a living organism no reference has yet been made. Living organisms always, or nearly always, appear to be marvellously 'adapted' to their physical environment. Yet this adaptation is not of the essence of the biological conception of an organism. We know, also, that organisms may develop which, in one way or another, are so misshapen or defective that they cannot survive, though they have all the essential characteristics of organisms. They maintain their existences as organisms for a short time, blindly struggling, as it were, to preserve the defects which make them incapable of surviving.

Organic life is 'blind': each organism blindly struggles to maintain its own existence or that of its species. We can only explain the actual marvellous and intricate 'teleological' adaptation of organism and physical environment by the fact that, as pointed out by Darwin and Wallace, those organisms which are not so adapted must disappear. Even if we could see far enough to be able to regard as organic the whole of 
what appears as inorganic, the entire world would still appear as a blind struggle between different organisms. Of this conflict, whether we regard it as conflict between organisms themselves, or between organisms and physical environment, we can give no biological interpretation, and are thus forced back on a physical interpretation. From the standpoint of ideal biology organism and environment would be one. The organism would be not something in a more or less foreign environment, but in its own environment, which it has grown in, and which has been part of its very nature from the outset. Of the actual foreignness or imperfection in the environment biology as such can give no account.

This discussion brings us to the subject of the last lecture. In the higher organisms, at least, we find distinct evidence of a quite new factor-consciousness. A conscious organism is, as it were, fighting the inorganic world, not blindly but with the weapons of that inorganic world itself. It answers blow with counterblow, and physical force with counter-force. 'The conscious organism is aware of the inor- 


\section{BIOLOGY AND PHYSICAL SCIENCES}

ganic world as such, and reacts as in presence of that world, whether it be real or unreal.

In concluding this lecture let us survey the progress made in our discussion. We have seen that the idea of the physical universe as a world of self-existent matter and energy is only a temporary working hypothesis by means of which we are able to introduce a certain amount of order and coherence into a large part of our experience. The fact that, as shown in the last lecture, this hypothesis breaks down in connection with the phenomena of life need not, therefore, puzzle us. The phenomena of life involve another and radically different conception of reality, and I have endeavoured to define this conception, and point out that it is actually used as a working hypothesis by biologists, and that by its means we introduce order and intelligibility into biology, whereas there is no such order or intelligibility if the mechanistic theory of life be adopted. The idea of life is nearer to reality than the ideas of matter and energy, and therefore the presupposition of ideal biology is that inorganic can ultimately be resolved into organic phenomena, and that 
PHYSICAL AND BIOLOGICAL REALITY 105

the physical world is thus only the appearance of a deeper reality which is as yet hidden from our distinct vision, and can only be seen dimly with the eye of scientific faith. We have seen, finally, that the ideal biological world is never completely realised. 


\section{LECTURE IV}

\section{PERSONALITY}

In the previous lectures I have endeavoured to follow out what is involved in our experience of living organisms looked at from a purely biological standpoint. - Actually, however, the higher organisms display characters which do not belong to the conception of them as mere organisms : for they are conscious-in conscious relations of perception and active response with their environment.

Let us try to realise more clearly what is involved in the conception of a conscious organism, or person. From the discussion in the previous lecture it is evident that we cannot mean an organism lighted up, as it were, by flashes of consciousness : for isolated flashes of consciousness, as Kant showed, do not exist. We must therefore put entirely out of court the theory that conscious life is simply a series 
of isolated states of consciousness which are the mysterious accompaniments of certain physical and chemical processes in the brain. Such a theory is merely a combination of obsolete philosophy with equally obsolete physiology. Nor can a conscious organism mean that the organism, or its brain, is the 'seat' of an independent and self-existent soul or Ego, of which consciousness is the activity. This theory involves the impossibilities which Hume and Kant so clearly pointed out. Nor, finally, is a conscious organism conscious merely of its own organic activity. It is certainly conscious generally of its own organic activity, though of the details of this activity it is either totally unconscious, or only dimly conscious. On the other hand, it is also clearly conscious of an outside environment distinguishable from its organic existence, and tending to further or hinder it: also of itself reacting in such a way as to control this environment more or less successfully. It is thus conscious both of itself as organism and of what does not directly belong to its organism-an Ego and a non-Ego. Both of these are inside its world, and somehow or 
other, as we saw in the previous lecture, that world of consciousness is the world of supreme existence : for the elements in that world-all that we perceive-exist only in their relations to one another as parts of one supreme whole.

At first sight this conclusion seems, perhaps, to have led us into the impossible position of an absolute idealism which is at the same time subjective idealism-the position that somehow the existence of the universe is bound up with the individual existence of a certain person, who was born, and will assuredly die, on certain dates. Such an interpretation is incorrect, as will be shown presently; but meanwhile let us follow out our analysis.

As Kant and his successors showed, the world as perceived is a world of elements which are not self-existent but exist only as related to one another-related temporally and spatially, as substance and accident, matter and energy, or as expressions of organic unity. If we look further at this world of perception we find that it is apparently centred in ourselves-in our own individual organism. It has a particular here 
and now, to which its spatial and temporal relations are referred. This particular here and now is apparently occupied by a particular self in which the material world of matter and movement is centred. But the particular self is not merely a portion of matter, but a living organism; and the surrounding world is not a world perceived merely as matter, but as matter in relation with the life of this organism. What I perceive is what interests me as an organism; and my voluntary reactions upon the surrounding world are reactions in the interest of my organism.

Let us be quite clear on this point, for it is of great importance. At first sight it may, perhaps, seem that the surrounding inorganic world is perceived merely as a physical world of matter and energy, or that if we seem to perceive it as anything else this is mere anthropocentric illusion. It is true that in practical life we regard the inorganic world from the standpoint of its practical relation to our own lives. The engineer or the workman treats the world from the utilitarian standpoint of its uses and hindrances to human life 
and development. But reality, we are accustomed to think, is something apart from this temporary and one-sided view of it, so that what we really see is simply a world of matter and energy, as described by the physical sciences.

If we look back, however, at the history of the gradual development of our scientific ideas, we find that they have one and all sprung out of the needs of practical life. The tradesmen who devised and used the balance, and the engineers who measured in footpounds and horse-power, had practical ideas of mass and energy long before men of science definitely formulated and extended these conceptions. The sciences are built up on ideas which have their roots in practical human needs. These ideas are changing and developing with human progress, and never escape from being anthropocentric. When separated from the mother earth of human experience they cease to live; and this is so whether the experience is that of ordinary practical activity or of laboratory experiments. We cannot separate our world from our interest in it. What we see in it is deter- 


\section{TELEOLOGICAL DETERMINATION 111}

mined by our attention, and our attention is determined by our organic needs.

Our conscious and voluntary reactions to the world outside us are similarly determined by reference to what is required for our organic maintenance. Hence teleological determination with reference to organic need extends to the whole of our experience. It is this which gives unity and coherence to the world of our conscious experience. Kant saw clearly the necessity of such a unifying factor in experience when he referred to the 'synthetic unity of apperception' as implied in all experience, in addition to the categories which he postulated.

What is implied in this teleological determination of the world of our experience? It is clear, in the first place, that the teleological determination is only imperfect. The things in the external world which supply our organic needs or hinder their satisfaction appear to have also an existence of their own which has no reference to us or our needs. A block of stone remains a block of stone whether it is of immediate interest to me as part of my house, or as just about to fall on 
my head, or is lying concealed beneath the surface of the earth, and only of potential value. In utilising the block of stone for my own purposes, I have to reckon with the fact that, owing to properties in it which have nothing to do with my present requirements, it may crumble away or split. The teleological determination of the stone in my experience is thus imperfect. I perceive it in part as of use to me, and I can only in part adjust it to my purposes. Nevertheless, in merely perceiving it as stone or even as mere matter, I am perceiving it as something of potential use or hindrance to me. However partially or imperfectly, it is, when so perceived, teleologically determined in relation to me; and were it not so it could not enter into the unity of my experience.

If I knew more about the piece of stone its teleological determination would be more perfect. If, for instance, I knew its exact chemical composition, and how to decompose it with ease into its elements, its potential value to me would possibly be greatly increased. And if I knew a means of liberating the enormous stores of energy locked up 
in the atoms of the stone, its potential value might be almost incalculable. If, finally, I knew what lies hidden behind the appearance of atoms, and energy, and all the other physical and chemical appearances in the stone, I could completely adjust myself to it. Its teleological relations to me would be entirely transformed: it would be wholly a part of myself, and the end of my scientific study of the stone would be completely attained.

We can in thought abstract from, or leave out of account, the teleological determination of our experience, and treat the external world as if the appearances in it existed entirely apart from their teleological relations to ourselves. In scientific thought we actually do make this abstraction, leaving out of account the fact that all our scientific ideas are human ideas, the product of human development, and gradually evolved to meet human needs. We can also regard human activity in relation to the external world as simply the action of one self-existent thing on other self-existent things, without any regard to the teleological determination of 
this activity in relation to human organic needs. For certain purposes this abstraction from reality is useful; but we must be clear that it is an abstraction from reality, and that in considering the nature of personality we cannot make any such abstraction. The apparent self-existent things in the form in which they appear to us are themselves the creation of our own thought-are machinery which we have made for our own purposes. The parts of this machinery may appear to exist independently of one another; but all are determined as parts, however imperfect, which we have made for our own purposes. Their imperfection is our own imperfection; for they are part of ourselves, and belong to our personality. We have made them in order to use them for certain purposes, and we do so use them. In scientific work we are not simply studying passively something which is apart from and independent of us : our real aim is just as much practical as that of any ordinary workman. He has to study things just as we do, and our study of them is only part of the gaining control of them, just as in his case. Our theories are practical 
theories, just as his are, though he is putting them to immediate practical use, while we are not.

The conclusion thus reached is that the world of our experience is a world of personality. We can reach this conclusion either from the purely philosophical side, with Kant and the other philosophers, through the abstract demonstration that the world we see is the world as we see it. Or we can reach it from the side of human history, through the more concrete demonstration that the world we see is the world which by painful human effort we have gradually learned to fashion in thought and action. The claim sometimes advanced on behalf of natural science that it deals with absolute reality, independent of man himself, cannot be maintained.

We must now examine more closely the difference between the conception of a person or conscious organism and that of a mere organism as such. The higher organisms are evidently conscious, like ourselves, though they may be aware of far less than we are. As we go down the scale of organic life we gradually lose the evidences of consciousness. We 
can also find no signs of consciousness in the greater part of the organic activities of our own bodies. Mere organic activity is evidently blind or unintelligent. An organism as such is in constant relation with its environment, as we have already seen, but only in so far as the environment enters into its organic life. To this extent the action and reaction between organism and environment is determined as a part of organic activity. Apart from this, however, the mere organism is at the mercy of the physical environment: it is helplessly swept hither and thither and learns nothing from experience: the physical environment appears to be foreign to it in just the same sense as the environment of a portion of matter is foreign to it.

Biology as such does not give us any rational account of the tossings about of the organism in the sea of its apparent physical and chemical environment. All that biology can do is to reveal to us the blind organic activity which is the one element of constancy and intelligibility throughout these tossings; and the tossings themselves appear to us as nothing more intelligible than the aimless 
and irrational change in an aimless and irrational world of matter and energy.

For the conscious organism, on the other hand, the physical environment is no longer something merely external, but is perceived, however dimly, and reacted to, as of practical significance and yet outside of immediate organic determination. It is through the fact that in perception and volition the external world is in real connection with the internal organic world that conscious life or personality distinguishes itself from mere organic life.

We must, it seems to me, draw a sharp and clear distinction between biology, which deals simply with organic life, and psychology, which deals with conscious life or personality. 'This distinction is similar in general nature to that which I have already endeavoured to draw between physics and biology. Just as biology is a more concrete science, nearer to reality, than physics and chemistry, so psychology is a more concrete science than biology. We can abstract from the psychological aspect of a man or animal, and regard him only from the biological aspect. 'This is, in fact, what we do in physiology. In regard to most of the н 2 
details of bodily activity there is little need for deliberate abstraction, since the psychological element lies only in the background. But when we come to deal with the bodily parts more immediately concerned in perception and voluntary response the case is very different. Perception, voluntary response, and conscious activity of every kind belong to personality, and therefore cannot as such be dealt with scientifically from the merely biological or physiological standpoint. We might as well attempt to establish physics on a basis which totally disregarded the facts on which the conceptions of mass and energy are based, as to establish psychology on a merely physiological basis. Physiological psychology, in so far as it is such an attempt, is nothing but a misbirth of modern times, inevitably doomed to perish, just as is bio-chemistry in so far as it is an attempt to establish physiology on a purely chemical basis.

Now all organic activity in a conscious organism is ultimately more or less under conscious control, directly or indirectly; and from this fact it might be argued that if physiological psychology is impossible, so also is the 
whole of the physiology of conscious organisms, since physiology cannot, as such, give any account of this conscious control. If it were maintained by physiologists that the physiological account of a man or animal is an ultimate and complete account this argument would be valid. 'There is, however, no reason why physiologists should take up such an untenable position. Physiology deals, and ought to deal, with living organisms just in so far as the observations relating to them can be ordered in terms of the conception of a living organism. Where, and in so far as, the conception of a mere organism fails, as in the facts relating to conscious activity, we must have recourse to another conception, that of personality.

It is evident that in applying the conception of personality to man or animal we leave out of account the details of organic activity. But the details are there, and the only account we are in a position to give of them is in terms of the lower or less concrete conception of mere organic activity. If we go still further into detail we are reduced to a still more abstract account in terms of physics and chemistry. 
Hence although in giving an account of perception and volition as a whole we make use of the conception of personality, and cannot otherwise state the facts, there is abundant room left for a physiological account of the sense organs, nervous system, muscular activity, etc., provided that we recognise that such an account always deals abstractly with the phenomena, for the sufficient reason that a fuller and more concrete account cannot at present be given. In the same way we treat the action of the muscles on the limbs, or of the limbs on the environment, or of the environment on the sensory organs, from the merely physical standpoint. This is an abstract method of treatment, as we have already seen ; but it is to some extent the only method available. Provided we do not make the mistake of confusing the physical account of the world with reality, we are perfectly justified in making all the use we can of this physical account. The mere physical facts, however, belong properly to neither physiology nor psychology.

Much of the most valuable part of our pliysiological knowledge results from the 
observation of activities of which we are conscious. In making these observations we deliberately disregard or abstract from the whole psychological aspect of the phenomena : we even take special precautions to exclude psychical interference. In this way we observe and analyse the physiology of the sense-organs, muscular movements, breathing, the intake of food and drink, etc. The methods used are exactly the same as if we were investigating something which is outside of direct conscious control, such as the circulation, or the secretion of urine; and it is a complete mistake to describe as psychology any such investigation in which we are observing something of which we are conscious. Psychology deals with personality, and observations from which all that is distinctive of personality is rigidly excluded have nothing to do with psychology. Conversely, psychological investigation has no place in physiology. The physiologist who treats of perception and volition is going outside his own subject, and sometimes does so in a quite illegitimate manner, endeavouring to state or explain psychological phenomena in terms of a conception which cannot be 
applied to them because it cannot describe them.

The man as a person is more than the man as an organism; but we must not make the mistake of supposing that he is anything different from his organism perceived and understood more fully. It is absolutely vain to attempt to separate in any other sense the personality of the man from his organic life. His character is, on a lower plane of our perception, organic character; his passions, on this plane, are mere organic instincts. To separate off the organic instincts as if everything connected with them were outside the man's real personality is to make the same kind of mistake as is made by the vitalists in physiology. The love between parent and child, or man and woman, may be looked upon, by those who are not attempting to see further into reality, as mere organic instinct; but in nothing else does personality in its distinctive sense manifest itself more clearly, and through nothing else can character be judged more certainly. The person is the whole man, and the organic aspect of him is only an abstract or partial aspect. 
We can now reach clear conclusions on the much debated question as to the relations between mind, organism, and matter. Clearly this relation is not a spatial one, capable of being stated in any sort of terms of interaction. The relation is simply one of different degrees of nearness to reality in the manner in which phenomena are described.

We may attempt to regard a man as $/$ simply a coloured extended patch or form. This is a very abstract or empty conception of a man; but for certain purposes it may be legitimate-for instance, if we are considering how much space the man occupies, or whether he will be visible against a certain background.

We can also attempt to regard him as about seventy kilogrammes of material with a certain external configuration, internal structure, and movements : such material consisting of a great variety of chemical molecules, acting upon one another and passing inwards and outwards in various ways. 'This is a much less abstract conception of the man, and for many purposes is extremely useful, 
and indeed quite sufficient. It is also the account which the mechanistic theory of life aims at giving in a complete form. Moreover, we cannot at present give any better account of much which we find in the man.

We can next attempt to regard the man as a living organism, blindly maintaining its structure and activity and fulfilling its organic function in relation to the species. This is the point of view of biology, freed from the trammels of the mechanistic theory of life; and this mode of regarding the man takes into account a great deal of what was entirely left out of account in the physical and chemical presentation of him. 'The purely biological account is evidently of enormous use, particularly in relation to medicine and social and economic activity.

4 - Lastly we can attempt to regard the man as a person, in conscious relation through perception and volition to his environment. 'This mode of regarding him includes all that was left out in the previous modes. The man as a person is thus no abstraction from reality, like the man as a mere form, or as an arrangement of material, or as a 
living organism. $\mathrm{He}$ is the real man; and his relation to the man as merely material, or as merely organism, is the relation of reality to an abstract and imperfect presentation of it. The man we see as a person is the actual man; he is neither a conscious automaton, if any trace of meaning could be attached to such a conception, nor a machine controlled by a soul or mind inside. The question of the relation of mind to body is a logical question; and the confusion which so easily rises on the subject is nothing but a logical confusion.

Our conception of the man as a person is evidently only a general conception, of which the details are very imperfectly filled in at the best. Of much that is in the man we can only form the blurred and imperfect conception afforded to us by the biological or physical view of him. Only by degrees do we learn to read his character in his actions, words, and features. But we know that his reality lies in his personality, because we cannot in any way reduce this personality to lower terms, such as matter or organism. 
My main object in these lectures was to map out as clearly as possible the position and aims of physiology, differentiating it on the lower side from the physical sciences, and on the higher side from the branches of knowledge which deal with personality. This plan has been carried out, in so far as time has permitted; but I should like to add some remarks as to the conception. of personality and what is involved in it.

The conclusion that the surrounding world is not a world of self-existent things, but assumes its actual appearance in perception and volition, may appear, at first sight, to involve the inference that the existence of the world of our experience is bound up with our own individual existence-with the here and now of a person who was born and will die. It is evident, however, that the personality of any individual is the spiritual inheritance of ages. Apart from that inheritance in which we have grown, we cannot imagine our existence. Just as the individual organism belongs to the species, and can only be understood as participating in its life, so the individual person lives not merely his 
own individual life, but the life of the race, and the still wider life that the race itself is living. 'There is nothing more certain than the existence and compelling power of duty which is no mere duty of the individual to himself, and of truth which is no mere truth for the individual. In personal existence there is always a here and now; but the here and now of action and perception is not merely my here and now, but the here and now of the wider personal life which lives in me.

To put the matter in different language, our personal existence implies in its very nature participation in a wider personal life. The individual person exists as belonging to that life. Even when he is living in what we regard as the most selfish manner he does not escape from this wider life: he is only living it in an imperfect manner, and in so doing realising his own personality imperfectly. It is the man who steadfastly endeavours to carry out, in the spirit and not merely in the letter, the social duties which have grown with him, who realises his own personality. In losing his individual personality in the 
wider personal life he realises his true personality.

This is a hard saying: for it represents a truth in the form which is hardest of all to grasp clearly, firmly, and at all times. Certainly no man succeeds in so grasping it. Reality is always presenting itself to us in ever-changing kaleidoscopic forms, in the confusion of which we cannot see clearly or act consistently. In these lectures I have attempted, following in the lines of some of the great leaders of human thought, to trace some of the main logical confusions, and to point out where and how they confuse us. In ordinary life we have usually to shut our eyes to these confusions, since we cannot at once see through them. The great practical leaders of humanity have usually ignored the confysion, and boldly proclaimed that their own picture is the true one, and the rest mere illusion. It is harder to see that the true picture is everywhere if we look close enough, but in an ever-developing form.

The astronomer or the physicist seems, at first sight, to be presenting to us a gigantic and absolutely inhuman universe, in which 
man and human activity is but a tiny speck. Most people simply shut their eyes to this picture in its entirety. Few have the courage to face it. But it was faced by the philosophers of the eighteenth century. Hume pointed out that there is one all-important element in the picture which most people leave out of account, and this is that the picture is only a picture. Kant and his successors taught us to see in part how the picture is painted, and to realise that it is only one expression of human personality - the personality typified in the lonely and heroic figure of Copernicus. Those who have read Heine's Deutschland will remember his account, scintillating with the flashes of his wonderful literary genius, of Immanuel Kant, whom he represented as the Robespierre of an intellectual revolution far more wide-reaching in its effects than the French Revolution. The victim of this intellectual revolution was pictured as no mere earthly king, but the God of Hebrew and Christian tradition. 'I can hear the bell. Kneel down. They are bringing the sacraments to a dying God.' Heine was right in his estimate of the importance of Kant's 
work. But it was the God of materialism, and not of Christianity, that was dying.

Another picture that is often presented to us nowadays is the ideal of men as perfect organisms. All our ills seem, it is argued, ultimately to arise from organic imperfections; and if we could only eliminate these by improving our material conditions, or by eugenic control of the population, all would be well with us. Care of the body thus appears as the all-important question. If we were nothing but unconscious organisms blindly struggling for existence, this mode of regarding humanity would doubtless be a correct one. It would have mattered more to our race that Shakespeare or Newton should have begotten children than that they should have done the work by which they are known. But we are not mere organisms: nor does our life-work die with us. Nor is it true that organic perfection, so far as we can ordinarily judge of it, is necessarily any true test of human fitness. It has been my lot to see many men and women who have distinguished themselves by showing the greatest of moral or intellectual qualities, and they present 
themselves to my memory as on the whole a rather weedy-looking collection, while the men or women who have looked like perfect animals have not infrequently been wholly incapable of filling the station into which they had chanced to be born.

Still another picture is that of men as each striving simply for his own individual interests, and of nations as similarly striving against one another. We find this picture pressed upon us, not merely by the oldfashioned political economists, but also from many other quarters. It is evident that men and nations do compete with and struggle against one another, and must be ready to do so whenever necessary. But we have only to go out of our arm-chairs into the real world to find that they are equally willing to cooperate with and help one another, even to the point of taking great risks or making great sacrifices. This is so not only with individual men, but also with nations. A wave of national feeling may quite easily carry a country into war in defence of another country, just as one man will readily risk his life to save another man, or simply to carry 
out his duty in whatever form it may present itself. The picture of men or nations as mere individuals blindly struggling against one another, or each working only in his own individual interest, is simply another of the illusions of imperfect logic, or of what comes to the same thing, one-sided and imperfect observation.

Another form of this picture is that of personal life as of a mere isolated individual, buffeted about, and perhaps now suffering or dying, in a world that seems wholly external. The individual may be nothing but a poor hypochondriac, or he may be broken by real physical misfortunes, or the failure of those whom he loved and trusted, or of some cause which he had worked for. For the man who is suffering or dying in consciously doing his duty there is probably no such illusion. It is harder to see that the man who has failed, perhaps through his own defects or those of others, or through what appears to have been mere mischance, can still be at one, and feel himself at one, with the wider personality that lives in him and will still live when he, as a mere individual, perishes. 
Philosophy leads us up to personality as the great central fact of the universe; and we have seen that this is not mere individual personality. Nor is it limited as the personality of country or species. However dimly we may see it, it is a personality which includes within itself our whole universe. If we follow out the line of thought initiated by Kant, and particularly the analysis of what is implied in truth and duty, no other conclusion is possible.

But what, it may be asked, of the time before conscious personality existed? This question is similar to that relating to the origin of life, and already discussed. We know nothing of such a time; and time and matter themselves are but expressions of personality. The logic of the universe is the logic of personality, and cannot, as it were, rise up against and destroy itself. It is the business of philosophy or of religion -for there is no real distinction between the two-to free us from the various illusions through which such a thing appears to be possible.

These illusions seem to rise like spectres 
on every side. What, for instance, of the history of the individual person? Was there not a time when, within his mother's womb, he had no conscious existence? And how did his individual personality come into being? Not only his bodily form, but all his moral and intellectual characteristics are inherited from or through his parents. Is not, therefore, his personality the mere outcome of material or purely organic conditions? Is not this rendered certain by the known fact that some organic defect-for instance, in his thyroid gland-may make him an idiot?

In practical life we must often, perforce, satisfy ourselves with such reasoning; but there is a petitio principic running through it all. It is the same petitio principii that runs through the whole materialistic conception of the universe. We as yet know nothing of the psychology of the fotus or the individual cell, just as our forefathers knew nothing of the physiology of the living cells which they mistook for mere drops of colloid material. We also know extremely little about what we call matter, though we do know enough about our ignorance of it to enable us to reject an 
THE WORLD A SPIRITUAL WORLD 135

argument based on the assumption that our ignorance is knowledge.

Looking back at the argument stated in the first lecture, we can see that it was based on a mere provisional hypothesis with regard to the nature of the external world. This hypothesis serves a useful though limited purpose; but we have seen that it is not, and cannot be, a true account of reality, whereas the materialistic argument was based on the assumption that it is a true account; and that matter and energy as such are realities which cannot be questioned. In actual fact we do not understand, except in the most imperfect manner, the reality which lies behind the appearance of a physical world. But we understand enough to be certain that this reality has, and can have, no existence apart from personality, since existence itself has no meaning apart from spiritual existence.

Philosophical discussion helps us to realise that on every hand we are surrounded by mysteries to be solved, and points out the paths of further investigation. Except by the combination of painful and accurate 
observation with equally painful and accurate thought and action, we cannot realise our true existence. This observation, thought, and action must also be the educated observation, thought, and action of personality, and must focus in itself the spiritual inheritance of personality.

In personality there is always the element of the here and now. New experience is always, as it were, welling up within it, and gradually taking the form of new truth and new duty. Personality is living, suffering, rejoicing, and working existence. This idea is clearly embodied in the Christian conception of God; and when we try to penetrate through the sensuous mist which blurs that conception we can see that our discussion has brought us very near to it.

In concluding these lectures I should like to summarise briefly the course of the argument. In the first lecture I stated as clearly as I could the arguments in favour of the mechanistic theory of life, and the fatal objections which may be urged against vitalism or animism. The second lecture was devoted to criticism of the mechanistic 
theory. I endeavoured to show that the experimental evidence which has been brought forward in support of this theory will not bear critical examination, and that the popular idea that the progress of physiology is in the direction of confirming or supporting the mechanical conception of life is a complete illusion. I then proceeded to discuss, in the light of biological facts, whether by any possibility the mechanistic theory may not still be correct. The result of this discussion was that there is no such possibility. The physical and chemical conception of the world breaks down absolutely and hopelessly in connection with the phenomena of life, however useful it actually is in connection with inorganic phenomena. It is, therefore, nothing but a working hypothesis of limited useful application.

The third lecture began with a brief discussion of the progress made by philosophy in discussing the ultimate validity of the physical and chemical conception of the universe; and it was shown that there is no ultimate validity in this account, so that we are quite free to employ another conception 
in interpreting biological facts. It was then shown that we do actually employ the fundamental working conception of living organisms as such, and that with the help of this conception we can bring order and intelligibility into biological investigation, and we are provided with a working hypothesis which is of the utmost practical value in biological work. This was illustrated by reference to the actual course of physiological investigation, and contrasted with the scientific impotence resulting from the adoption of the mechanistic theory, which is only capable of presenting the facts in a more partial or abstract manner. It was also pointed out that the ultimate ideal of biology is to bring within the scope of biological conceptions even the phenomena which we at present interpret as inorganic.

In the fourth lecture the phenomena presented by conscious organisms or persons have been considered. It was shown that the relation of a person to his surrounding world with which he is in contact through perception and volition is not a mere external relation, since his surrounding world is 
teleologically determined in relation to his organic life. It is a mere logical illusion to regard the world we perceive as independent of its relations to us in perception and volition. The visible world around us is a world moulded by our personality, and there is no other world. In scientific work we can abstract from, or disregard, the psychological aspect of things, but in so far as we do so we are dealing with abstractions. The relations of personality, mere organism, and matter are relations of increasing abstraction from reality. Just as the individual organism can only be understood as participating in a wider life, so the individual person exists only in participating in a wider personal existence. He can only realise his true personality in losing his personality as a mere individual. Personality is the great central fact of the universe. This world, with all that lies within it, is a spiritual world.

Printed by T. and A. Consta ble, Printers to His Majesty at the Edinburgh University Press 



\section{WORKS BY THE VISCOUNT HALDANE OF CLOAN.}

\section{THE PATHWAY TO REALITY.}

THE GIFFORD LECTURES 1902-1904.

2 vols. Large Crown 8vo. Ios. 6d. net each.

Vol. I. - The Meaning of Reality.

The Criticism of Categories.

Vol. II.-Absolute Mind.

'An important and interesting work which is original in its statement. . . These two volumes are eminently stimulating, and, what can seldom be said of the works of idealist philosophers, they will be quite intelligible to any thoughtful reader.'-Westminster Gazette.

'. . . this profound and rather fascinating book.'-Morning Post.

'A noble and suggestive book, which does not claim to answer all objections, but rather to be an aid to the interpretation of the riddle of life.' -The Standard.

\section{EDUCATION AND EMPIRE.}

\section{ADDRESSES ON TOPICS OF THE DAY.}

Crown 8vo. 5s. net.

'Well informed, earnest, and well written.'-The Scotsman.

'It is not, however, solely or mainly because they are thoughtful and instructive contributions towards the solution of specific problems of our national life that we should be glad to secure for Mr. Haldane's addresses the widest possible circulation; but rather because they are throughout inspired by a great idea, and because, while professedly dealing with only one or two aspects of the Imperial problem, they furnish us with a strong stimulus towards the formation of loftier conceptions of our duty as citizens of the Empire in every department of our Imperial life.'-Morning Post.

\section{UNIVERSITIES AND NATIONAL LIFE.}

Second Edition, with an added chapter, entitled-Great Britain and Germany: A Study in National CharacTERISTICS.

\section{Crown 8vo. 2s. 6d. net.}

' The subjects dealt with in these papers are of far wider scope than would be imagined from this title. So far as it is possible to summarise the lesson which they teach, they may be said to describe from various standpoints the ideal character, and to sketch out the best methods of developing it.'-Spectator. 


\section{THE PROGRESSIVE SCIENCE SERIES}

ThE GLOBE says: 'So many books of popular science are published at the present day which are not scientific at all, that it is a relief to welcome another volume of the excellent Progressive Science Series issued by Mr. John MurRay. They have all the moderation of statement and fulness of detail which is essential.

\section{PROBLEMS OF LIFE AND REPRO. DUCTION. By Marcus Hartog, M.A., D.Sc., Professor of Biology in the University, Cork. With Illus- trations. 7s. $6 d$. net.}

EARTHQUAKES : In the Light of the New Seismology. By Clarence Edward Dutton, Major in the United States Army. Illustrated. 6s. net.

HEREDITY. By J. Arthur Thomson, Regius Professor of Natural History in the University of Aberdeen. With numerous Illustrations. New and revised edition. 9s. net.

'We all know books of science which we ought to read with pleasure, but to which we turn with shrinking. Full perhaps of new facts and ideas, they are so expressed as to bore consumedly. "Heredity" belongs to another category. He who runs may read, even if he be a beginner, and he who reads will probably not cease to run until he has traversed the last page.'-Nature.

\section{THE INTERPRETATION OF RADIUM.}

Being the substance of six free popular experimental Lectures delivered at the University of Glasgow, I908. By FREDERICK SODDY, M.A., Independent Lecturer in Physical Chemistry and Radioactivity in the University of Glasgow. With Illustrations. Third Edition, revised and enlarged. 6s. net.

'A most admirably conceived exposition which does not seek merely to attract us by turning marvels, at once outstripping our imagination and humbling our conception, into cheap popular gazing-stocks, but rather supports its unfailing charm by the legitimate interests-pointed here into a fascination that may arrest even an habitually desultory reader-of science at once genuinely and delightfully taught.'-Spectator. 


\section{HYGIENE OF NERVES AND MIND IN} HEALTH AND DISEASE. By August FOREL, M.D. Translated from the German by AUsTiN Aikins, Ph.D. 6s. net.

\section{CONTENTS}

Introduction. PART I. Mind, Brain, and Nerves in their Normal Condition. PART II. Pathology of the Nervous Life. PART III. Hygiene of the Mental Life and of the Nervous System-Appendix-Index.

\section{THE STUDY OF MAN. An Introduction to} Ethnology. By Professor A. C. HADdon, D.Sc., M.A. With numerous Illustrations. $6 s$. net.

\section{THE PROBLEM OF AGE, GROWTH,} AND DEATH. A Study of Cytomorphosis. Based on Lectures at the Lowell Institute, March 1907. By Charles S. Minot, LL.D. (Yale, Toronto), D.Sc. (Oxford); James Stillman Professor of Comparative Anatomy in the Harvard Medical School; President of the Boston Society of Natural History. With numerous Illustrations. 6s. net.

\section{CONTENTS}

Old Age-Cytomorphosis: the Cellular Changes of Age-Rate of GrowthDifferentiation and Rejuvenation-Regeneration and Death-The Four Laws of Age-Growth of Rabbits-Growth of Chickens-Death of ProtozoaLongevity of Animals-Theory of Life-The Age-reckoner-Index.

\section{INFECTION AND IMMUNITY. With}

Special Reference to the Prevention of Infectious Diseases. By George S. Sternberg, M.D., Surgeon-General (retired) U.S. Army. 6s. net.

\section{CONTENTS}

PART I. General Remarks-Disease Germs-Channels of Infection-Sus. ceptibility to Infection-Disinfection-Tests of Disinfection-Disinfection by Heat-Sunlight as a Disinfectant-Disinfection by Gases-Chemical Disinfectants - Natural Immunity - Acquired Immunity - Antitoxins - Index. PART II. Consists of Twenty Chapters, each dealing with one of the more Important Infectious Diseases. 


\section{GOMPARATIVE PHYSIOLOGY OF THE BRAIN AND COMPARATIVE PSYCHOLOGY. By Jacques Loeb, M.D., Pro- fessor of Physiology in the University of Chicago. With Illustrations. $6 s$. net.}

THE STARS. A Study of the Universe. By Professor Simon Newcomb. With Illustrations. 6s. net.

Professor Newcomb gives in this book a fascinating account of the wonderful advances of our generation in the knowledge of the fixed stars. In its preparation he has had the assistance of a number of friends and colleagues, who have supplied him with the material necessary to the presentation of their latest researches.

\section{THE SOLAR SYSTEM. A Study of Recent}

Observations. By Charles LANe Poor, Professor of Astronomy in Columbia University. 6s. net.

The tides and tidal evolution, subjects but briefly treated in most astronomical works, are given considerable space in the present volume, and Mars and the so-called Martian canals, about which so much has been written, are somewhat fully dealt with.

CLIMATE. Considered especially in Relation to Man. By Robert De Courcy Ward, Assistant Professor of Climatology in Harvard University. With Illustrations. $6 s$. net.

This work is based on lecture-notes prepared for the students of Harvard University. Its aim is to co-ordinate and to set forth clearly and systematically the broader facts of climate in language as free as possible from technicalities. At the same time the needs of the teacher and student have been kept constantly in mind, and the subject-matter has been arranged in such a way as seems best to adapt it for purposes of thorough study.

\section{RIVER DEVELOPMENT. As illustrated by the} Rivers of North America. By Professor I. C. Russell. With Illustrations. $6 s$. net.

\section{CONTENTS}

To the Reader-The Disintegration and Decay of Rocks-Laws governing the Streams-Influence of Inequalities in the Hardness of Rocks on Riverside Scenery-Materials carried by Streams in Suspension and in Solution -Stream Deposits-Stream Terraces-Stream Development-Some of the Characteristics of American Rivers-The Life-history of a River-Index. 


\section{A BOOK OF WHALES. By F. E. BeDdard, M.A.,}

F.R.S. With 40 Illustrations by Sidney Berridge. $6 s$. net.

A distinct gap in the literature relating to whales has been filled by this book, for it provides in a comparatively small compass a general account of this group of mammals. The aim has been to produce a solid book tempered by anecdote. It is not a monograph of the Cetacea; but on the other hand, at least, the main facts of structure and mode of life of these interesting and remarkable creatures are given.

\section{THE GROUNDWORK OF SCIENCE.}

A Study of Epistemology. By St. George Mivart, M.D., Ph.D., F.R.S. 6s. net.

\section{CONTENTS}

Introductory - Catalogue of Sciences - The Objects of Science - The Methods of Science-The Physical Antecedents of Science-The Psychical Antecedents of Science-Language and Science-Intellectual Antecedents of Science-Causes of Scientific Knowledge-The Nature of the Groundwork of Science.

EARTH SCULPTURE: or, the Origin of Land-forms. By James Geikie, LL.D., D.C.L., F.R.S., etc., Murchison Professor of Geology and Mineralogy in the University of Edinburgh. Second Edition. With numerous Illustrations. 6s. net.

VOLCANOES : Their Structure and Significance. By T. G. Bonney, D.Sc., F.R.S., Emeritus Professor of Geology at University College, London. Third (new and enlarged) Edition. With numerous Illustrations. 6s. net.

' I have endeavoured to lead the reader through descriptions of the varied phenomena of volcanic action in the present and in the past towards ascertaining by inference the cause, or causes, of eruptions. For this reason I begin by an account of the "living volcano," choosing instances which may exhibit it (to continue the metaphor) at every stage from birth to death. Next I conduct the reader to the dissecting theatre, and point out what may be discovered in this method of study. I then recount the geological history of volcanoes in a single country, with a view of bringing out the changes in the position of vents, and in the nature of ejected materials, and, lastly, I describe the distribution of volcanoes either at present or in comparatively recent times, in the hope of finding something suggested by their geographical position and modes of occurrence. In the last chapter I sum up the results to which our investigations have apparently pointed, and endeavour to ascertain the conclusions to which they lead.'-Extract from Professor Bonney's Preface. 


\section{WORKS OF CHARLES DARWIN}

MR. MURRAY, whose house for fifty years has published the Works of CHARLES DARWIN, issues the following:

*Origin of Species by Means of Natural Selection. $6 s$. Popular Editions, $2 s .6 d$. net and Is. net.

* Descent of Man; and Selection in Relation to Sex. Woodcuts. Popular Edition, 2s. 6d. net.

Different Forms of Flowers on Plants of the same Species. Crown $8 v 0,7 s .6 d$.

*Expression of the Emotions in Man and Animals. With Illustrations. Crown 8vo, 12s. Popular Edition, 2s. $6 \%$. net.

*Formation of Vegetable Mould through the Action of Worms. Illustrations. $6 s$. Popular Edition, 2s. $6 d$. net.

*Insectivorous Plants. Woodcuts. Popular Edition, 2s. $6 d$, net.

* Journal of a Naturalist during a Voyage Round the World. Library Edition. 21s. Popular Edition. With Illustrations, 2s. $6 d$. net.

* Movements and Habits of Climbing Plants. Woodcuts. Popular Edition, 2s. $6 d$. net.

Cross and Self-Fertilization in the Vegetable Kingdom. Crown 8vo, 9 s.

*Variation of Animals and Plants under Domestication. Woodcuts. 2 Vols. 15 s. Popular Edition. 2 vols. 5s, net.

*Various Contrivances by which Orchids are Fertilized by Insects. Woodcuts. Crown $8 \mathrm{vo}, 7 s .6 d$. Popular Edition, 2s. 6 d. net.

Life and Letters of Charles Darwin. With an Autobiographical Chapter. Edited by his son, FRANCIS DARWIN, F.R.S. Portraits. 3 Vols. $8 \mathrm{vo}, 36 s$.

[Arrangements have been made with booksellers enabling them to offer special terms for this work.]

${ }^{*}$ Condensed Edition in I Vol. 2s. 6 d. net.

More Letters of Charles Darwin. A Record of his Work in a hitherto unpublished Series. Edited by FRANCIS DARIwIN and A. C. Seward. Portraits. 2 Vols. Demy 8 vo, 32s, net.

The Volumes marked * have been issued recently in a uniform edition in green cloth, large crown 8vo, 2s. $6 d$. net each. 


\section{WORKS ON MEDICINE}

\section{AND SCIENCE}

THE TREATMENT OF TUBERCULOSIS BY MEANS OF THE IMMUNE SUBSTANCES (I.K.) THERAPY. An Introduction to Carl Spengler's work on Immunity and Tuberculosis. By WALTER H. FEARIS, formerly Demonstrator of Botany, University College, Reading. With a Foreword by Dr. CARL SPENGLER. Large Crown 8vo. 6s. net.

' There is no doubt that this little volume is a valuable addition to current literature on Tuberculosis, and the medical profession should be much indebted to Mr. Fearis.'-Medical Times.

\section{INDUCED GELL-REPRODUGTION} AND CANCER. The Isolation of the Chemical Cause of Normal and of Augmented, Asymmetrical Human Cell-division. By Hugh Campbell Ross, M.R.C.S. (Eng.), L.R.C.P. (Lond.), with the Assistance of JoHN WESTRAY Cropper, M.B., M.Sc. (Liv.), M.R:C.S. (Eng.), L.R.C.P. (Lond.). With numerous Illustrations. Demy 8vo. I 2s, net.

FURTHER RESEARGHES INTO INDUCED GELL-REPRODUCTION AND

CANCER. Consisting of Papers by H. C. Ross, J. W. Cropper and E. H. Ross. (The John Howard M'Fadden Researches.) With Illustrations. 2 vols. Demy 8vo. 3s. $6 d$. net each.

DISEASES OF THE SKIN. By ERNesT Gaucher, Professor of Cutaneous and Syphilitic Diseases at the Faculty of Medicine, and Physician to the St. Louis Hospital, Paris. Including Radiumtherapy. By Drs. Wickham, Degrais, and Domenici. Translated and Edited by C. F. Marshall, M.Sc., M.D., F.R.C.S., Surgeon to the British Skin Hospital; late Assistant Surgeon to the Hospital for Diseases of the Skin, Blackfriars. With numerous Illustrations. I 5 s. net. 


\section{WORKS BY \\ THE LATE SIR RÜBERT W. BOYCE.}

\section{YELLOW FEVER AND ITS PRE-}

VENTION. A Manual for Medical Students and

Practitioners. With numerous Plans and Illustrations.

Medium 8vo. Ios. $6 d$. net.

This practical manual is a summary of the author's experiences and investigations on Yellow Fever in New Orleans, Central and South America, the West Indies and West Africa, and the subject is treated very completely, historically, geographically, and clinically. It also contains chapters on Treatment, Pathology, Diagnosis, and Epidemiology. Prophylaxis and Entomology have a complete section to themselves. The book is illustrated by some sixty figures, maps, and charts, and is intended as a practical manual for the medical student and practitioner.

\section{MOSQUITO OR MAN? The Conquest of the} Tropical World. Third Edition. Revised and Enlarged. With numerous Illustrations. Medium 8vo. Ios. $6 d$. net.

' This very interesting volume cannot fail to bring home to the reader the vast importance, economic as well as scientific, of this new conquest of the tropical world. The text is elucidated by numerous plates from photographs which illustrate not only several of the insects concerned in the propagation of disease, but views of anti-mosquito brigades, screened wards in hospitals, houses in course of fumigation, and many other scenes and objects bearing upon the contents of the book.'-Lancet.

'A book which gives us for the first time a thoroughly complete up-todate history of a branch of parasitology, and dealing with the most wonderful of all the manifestations connected with the development of modern medicinal science. In "Mosquito or Man?" the Dean of the Liverpool School of Tropical Medicine has given to the world a masterpiece of lucid exposition of the nature of the problem which Manson, Ross, and others have gone so far to solve.'-Liverpool Journal of Commerce.

\section{HEALTH PROGRESS AND ADMINIS- TRATION IN THE WEST INDIES. Second Edition. Medium 8vo. With Illustrations. Ios. $6 d$. net.}

' From beginning to end the book is full of interest, and its perusal may be warmly commended, not only to members of the medical profession, but to all who, for purposes of business or pleasure, find themselves from time to time called upon to visit the tropical outposts of the Empire. It is conspicuous, from the bookman's point of view, for the attractiveness of its style and the beauty of its illustrations.'-British Medical Journal. 


\section{THE PREVENTION OF MALARIA. By}

Major Sir Ronald Ross, F.R.S., C.B., Professor of Tropical Medicine at the University of Liverpool. With Contributions by twenty of the Leading Experts. With Illustrations. Demy 8vo. 2 Is. net.

'A thoroughly sound and comprehensive treatise; Major Ross and his colleagues have turned out work worthy of their high reputations. The student of malaria in all respects will find in this work the most complete exposition of the subject in medical literature.'-Lancet.

' Rarely indeed has one the pleasure of reading so masterly an analysis as this of such an intricate and technical subject.'-Hospital.

\section{A SUMMARY OF FACTS REGARDING MALARIA.} Suitable for public instruction. Reprinted from the above. $2 d$.

\section{ALSO BY THE SAME AUTHOR}

\section{PHILOSOPHIES. In Paper Cover. Is. net.}

A series of verses written in India between 1881 and I889, mostly in connection with the author's researches on Paludism.

\section{CHILDREN IN HEALTH AND DISEASE.}

A Study of Child-Life. By David Forsyth, M.D., D.Sc., Physician to the Evelina Hospital for Sick Children, Assistant Physician (late Physician in Charge of the Children's Department) and Joint Pathologist, Charing Cross Hospital. Demy 8vo. ros. $6 d$. net.

'The physiology and psychology of the child at every stage of its existence is fully dealt with, together with the bearing thereon of the work of health visitors, the Notification of Births Act, and other points connected with the functions of public health authorities. The situation of the school buildings, drainage, closet accommodation, design of class-rooms, arrangement of work, treatment of infectious diseases, medical inspection, class-room hygiene, and the training of defective children of every type, are among the many subjects which receive attention. The essence of the book, however, is to be found in the author's view of the evil results of treating the different aspects of child-life as entirely distinct from one another, and of the great importance of close co-operation between the public health and education departments.'-Official Circular of the County Councils Association. 


\section{A HANDBOOK OF PHYSIOLOGY. By}

W. D. Halliburton, M.D., F.R.S., Professor of Physiology, King's College, London. Eleventh Edition, being the Twenty-fourth of Kirkes'. With nearly Six Hundred Illustrations, including some Coloured Plates. Large Crown 8vo. I5s. net,

'One of the best manuals for the student which we possess ... the book is an eminently trustworthy one, and will prove a valuable foundation for, and introduction to, the large treatises on physiology.'-Lancet.

'The popularity of this excellent student's text-book is shown by the fact that a new edition is called for every year.'-British Medical Journal.

\section{A PRIMER OF PHYSIOLOGY. By Professor}

E. H. Starling, F.R.S. Illustrated. F'cap 8vo. is.

'This little book represents the nearest approach to the ideal primer of physiology that has yet been produced. In it the leading facts of physiology are expounded in a masterly manner-made, in fact, accessible to very modern capacities. The direct and simple style in which it is written, and its freedom from all but essential technical terms, render it a model of lucidity, and at the same time extremely interesting reading.' -Education.

\section{A MANUAL OF PATHOLOGY. Handbook} for Students. By Sidney Martin, M.D., F.R.S., F.R.C.P., Professor of Pathology, University College. With numerous Woodcuts from Micro-Photographs. Medium 8vo. I 5 s. net.

' This work is of such high excellence, and the difficult task of giving a complete survey of such a rapidly-growing subject as general pathology has been so well accomplished, that, in spite of the criticism we have offered, we can heartily recommend the work to students of pathology. In general terms it maintains the highest standard of the school from which it emanates.'- Lancet.

'Is excellent and superior, we think, to any other work of the kind in the English language.'-Hospital.

\section{THE TREATMENT OF SOME ACUTE VISCERAL INFLAMMATIONS, AND OTHER PAPERS. By David B. Lees, M.A., M.D., Cantab., F.R.C.P. Lond., formerly Scholar of Trinity College, Cambridge; Senior Physician to the Hospital for Sick Children, Great Ormond Street; Physician to St. Mary's Hospital. Crown 8vo. 6s. net.}




\section{THE BACTERIOLOGY OF MILK. By}

Harold Swithinbank, of the Bacteriological Research Laboratory, Durham, and Sir George Newman, M.D., F.R.S.E., D.P.H., Chief Medical Officer, Board of Education. With Special Chapters also by Dr. Newman on Spread of Disease by Milk and the Control of the Milk Supply. With numerous Illustrations. Royal 8vo. 25s. net.

' Ought to find a place in the library of every medical officer of health and of every milk-producer. Scientific in method and lucid in exposition, the authors have given us a really invaluable text-book. . . We are glad to commend this book as one of the most valuable of recent English contributions to the science of public health. ${ }^{\prime}-$ Spectator.

\section{BACTERIOLOGY AND THE PUBLIC} HEALTH. By Sir Grorge Newman, M.D., F.R.S. Edin., D.P.H., Chief Medical Officer, Board of Education. With numerous Illustrations. Medium 8vo. 21s, net.

'The present work, though nominally a third edition of "Bacteria in Relation to the Economy of Nature, Industrial Processes and the Public Health," is virtually a new book, written with the object of supplying all that is necessary for the student of hygiene and the officer of health to know, so far as every-day problems of sanitation and preventive medicine demand. ... Dr. Newman has done a good work in producing a treatise which places at the service of the community what is known about all these topics.' -Daily Telegraph.

\section{THE RECENT DEVELOPMENT OF PHYSICAL SCIENCE. By W. C. D. WнЕтнам, M.A., F.R.S. Illustrated. Large Crown 8vo. 5s. net.}

The Philosophical basis of Physical Science-The liquefaction of Gases and THe Absolute Zero of TemperatureFusion and Solidification-The Problems of Solution-The CONDUCTION OF ELECTRICITY THROUGH GASES-RADIO-ACTIVITY Atoms AND ÆTHER-Astro-Physics-INDEX.

\section{RECENT ADVANCES IN THE STUDY OF VARIATION, HEREDITY AND EVOLUTION. By ROBERT H. LOCK, M.A., Fellow of Gonville and Caius College, Cambridge. With Portraits and other Illustrations. Crown 8vo. 5s. net.}




\section{THE NERVOUS SYSTEM OF VERTE-}

BRATES. By J. B. Johnson, Ph.D., Professor of Zoology in West Virginia University. With One Hundred and Eighty Illustrations. I5s. net.

\section{CONVERGENGE IN EVOLUTION. By}

ARThUR Willey, D.Sc., Lond.; Hon. M.A., Cantab.; F.R.S. With Diagrams. Demy 8vo. 7s. $6 d$. net.

This work brings together some scattered facts of parallel development of outward form and internal structure in the animal kingdom, introducing new cases and fresh interpretations. It is, taken as a whole, an original contribution to the theory of organic evolution, with special reference to the forms of animal life.

\section{THE HEREDITY OF ACQUIRED CHAR-} ACTERS IN PLANTS. An Aspect of the true Darwinism based on Personal Observations and Experiments. By the Rev. Prof. Grorge Henslow. With Illustrations. Demy 8vo. 6s. net.

The object of this work is to substantiate Darwin's alternative explanation of Evolution, which replaces his theory of 'The Origin of Species by Means of Natural Selection.' He maintained that new forms arose by the 'direct action of changed conditions of life,' and that, if these persisted for several generations, the variations produced by them would be hereditary. The author herein describes experiments and observations which entirely confirm this later view of Darwin, held by him in 1876 . It is precisely the same as is that of all plant-ecologists of to-day.

\section{NOTEWORTHY FAMILIES (SCIENCE).}

An Index to Kinships in near degrees between persons whose achievements are Honourable, and have been publicly recorded. By Francis Galton, D.C.L., Hon. D.Sc. Camb., F.R.S., and EDgar Schuster, Galton Research Fellow in Natural Eugenics. Crown 8vo. 6s. net.

\section{MICROSCOPY. The Construction, Theory, and Use} of the Microscope. By Edmund J. SpitTa, F.R.A.S., F.R.M.S., etc. With numerous Diagrams and Illustrations. Second Edition. I2s. $6 d$. net. 


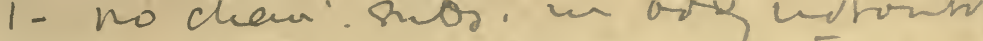

2. Mrbiall cou be sy und theiso.

5. seq. Giol = chan + raypiex.

8. "hir activit eo-ovinialed.

13. Gromk theainte of bis tees on chan' stimuli.

16. usuing resewt9. his ors. frome in tab.

4. nitalutic thy -

252 - ansuren livi

32. mech". Lapoun the Jank.

35. Loeb's hon-2equitur.

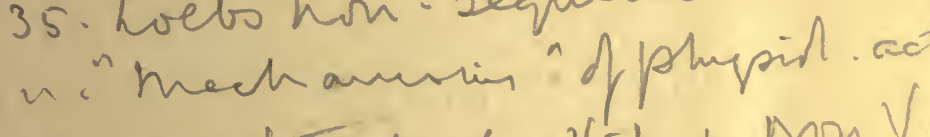

4l. his brial of - Vis $+\mathrm{mon} V$

43. mech "his hasper batei

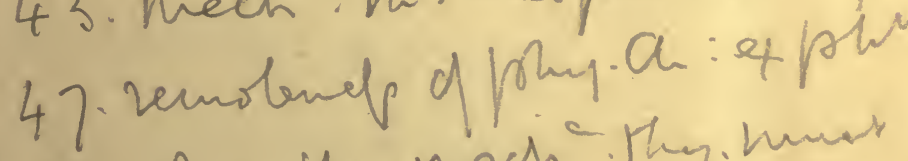

+ 53. Whor the reche thy. hums astainc-

55 does germ tham ef Maí $5 \delta$. medich $^{c}$ Mheres $=$ imforse G. Refuses med c prepaigly. 71. spentre qen concepr". thife

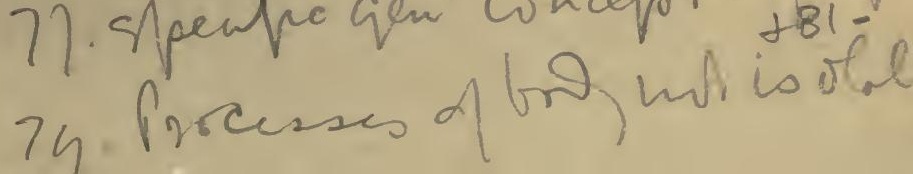


7. Geasting -

2. bor) a. a lismy organ " havent the vourcl as Nerts.

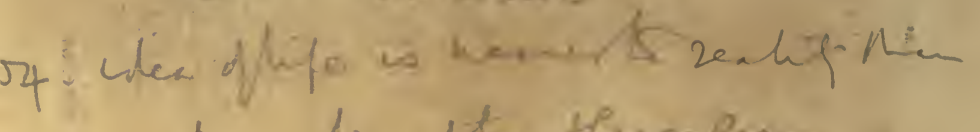
idas f mate therfy-

7). ansurns lefe - notr sen 1

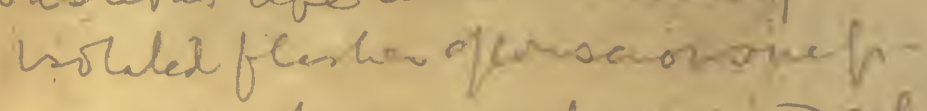

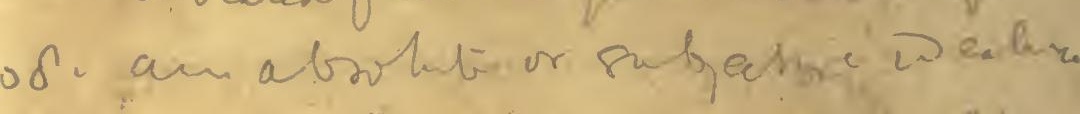
15. wonedfetparience is toonses

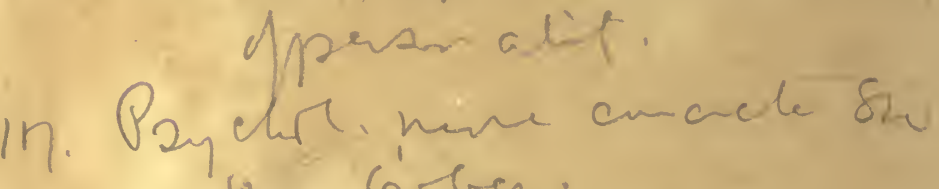
hen Girsen.

122 miman perisn mane him as organ

123. apploroches keatif.

126 personalitin 1 indivion - spirl. nulare 7 qo.

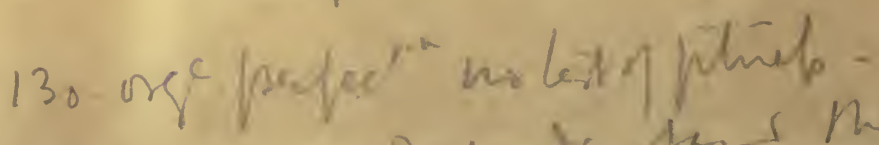

135. loc do not motersters the reabtbchant appce aphepd an

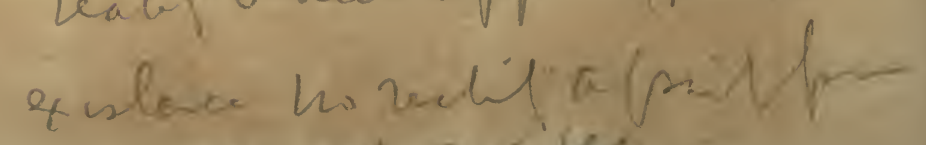
anstecise 


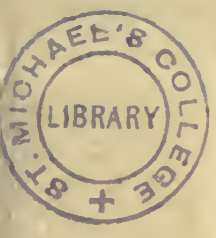

136. Persmabf 8t' itee Ur u. funm an $x$

HALDANE, J.S.

$2 \mathrm{H}$

331

Mechanism, life and personality.H3

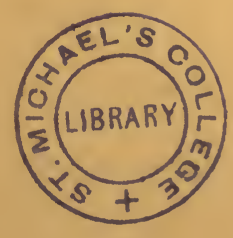


